\title{
Energy and water saving by using modified closed circuits of drip irrigation system
}

\author{
Hani Abdel-Ghani Mansour ${ }^{1 *}$, Mohamed Yousif Tayel ${ }^{1}$, David A. Lightfoot ${ }^{2}$, \\ Abdel-Ghany Mohamed El-Gindy ${ }^{3}$ \\ ${ }^{1}$ Water Relations and Field Irrigation Department, National Research Centre, Giza, Egypt; *Corresponding Author: \\ hanimansour88@yahoo.com \\ ${ }^{2}$ Soil \& Plant and Agricultural Systems Department, Southern Illinois University, Carbondale, USA \\ ${ }^{3}$ Agricultural Engineering Department, Faculty of Agriculture, Ain Shams University, Cairo, Egypt
}

Received 22 June 2010; revised 28 July 2010; accepted 3 August 2010.

\section{ABSTRACT}

The aim of this research was determine the energy and water use efficiencies under the modification of closed circuit drip irrigation systems designs. Field experiments carried out on transgenic maize (GDH, LL3), (Zea Mays crop) under two types of closed circuits: 1) One manifold for lateral lines or Closed circuits with One Manifold of Drip Irrigation System (CM1DIS); 2) Closed circuits with Two Manifolds of Drip Irrigation System (CM2DIS), and 3) Traditional Drip Irrigation System (TDIS) as a control. Three lengths of lateral lines were used, 40, 60, and 80 meters. PE tubes lateral lines: $\mathbf{1 6} \mathbf{~ m m}$ diameter; $30 \mathrm{~cm}$ emitters distance, and GR built-in emitters 4 Iph when operating pressure 1 bar under Two levels slope conditions $0 \%$ and $2 \%$. Experiments were conducted at the Agric. Res. Fields., Soil and Plant \& Agric. System Dept., Agric. Faculty, Southern Illinois University, Carbondale (SIUC), Illinois, USA. Under $0 \%$ level slope when using CM2DIS the increase percent of Energy Use Efficiency (EUE) were 32.27, 33.21 , and $34.37 \%$ whereas with CM1DIS were $30.84,28.96$, and $27.45 \%$ On the other hand when level slope $2 \%$ were with CM2DIS 31.57, 33.14, and 34.25 while CM1DIS were 30.15 , 28.98, and 27.53 under lateral lengths 40,60 and $80 \mathrm{~m}$ respectively relative to TDIS. Water Use Efficiency (WUE) when level slope $0 \%$ under CM2DIS were $1.67,1.18$, and $0.87 \mathrm{~kg} / \mathrm{m}^{3}$ compared to $1.65,1.16$, and $0.86 \mathrm{~kg} / \mathrm{m}^{3}$ with CM1DIS and $1.35,1.04$, and $0.75 \mathrm{~kg} / \mathrm{m}^{3}$ with TDIS whereas with level slope $2 \%$ when using CM2DIS were $1.76,1.29$, and $0.84 \mathrm{~kg} / \mathrm{m}^{3}$ compared to $1.77,1.30$, and $0.87 \mathrm{~kg} / \mathrm{m}^{3}$ with CM1DIS and $1.41,1.12$, and $0.76 \mathrm{~kg} / \mathrm{m}^{3}$ (for lateral lengths 40,60 , and 80 meters respectively). Water saving percent varied widely within individual lateral lengths and between circuit types relative to TDIS. Under slope $0 \%$ level CM2DIS water saving percent values were $19.26,12.48$, and $14.03 \%$; with CM1DIS they were $18.51,10.50$, and $12.78 \%$; and under slope level $2 \%$ with CM2DIS they were $19.93,13.26$, and $10.38 \%$ and CM1DIS were 20.49 , 13.96 , and $13.23 \%$ (for lateral lengths $40,60,80$ meters respectively). The energy use efficiency and water saving were observed under CM2DIS and CM1DIS when using the shortest lateral length $\mathbf{4 0}$ meters, then lateral length $\mathbf{6 0}$ meters, while the lowest value was observed when using lateral length $\mathbf{8 0}$ meters this result depends on the physical and hydraulic characteristics of the emitters, lateral line uniformity, and friction losses. CM2DIS was more energy use efficiency, EUE, water saving, and WUE than either CM1DIS or TDIS.

Keywords: Drip Irrigation; Closed Circuits; Energy Use Efficiency; Water Use Efficiency

\section{INTRODUCTION}

Drip irrigation system cutting edge technology in irrigation has many advantages and is accompanied by some of the problems and constraints as a problem low compressor water at the end of irrigation lines subsidiary has been proposed the development of closed-circuit by adding some modifications to the traditional system of drip irrigation to overcome this problem. According to increasing areas irrigated by drip system in the Egyptian desert at high rates, too, where this approach is successful for the irrigation of fruit trees and some crops of vegetables and field crops. 
The unique drip irrigation system on the other that he is part of the moisten the soil only and the other parts remain dry throughout the season. This results in partial hydration many benefits and few problems. Known as the drip irrigation system so that it is adding water to the soil directly in quantities close to field capacity. It is entirely appropriate term for plant growth in the form of small droplets to the plant roots where he pays a compressor under low water ranges between $70 \mathrm{~cm}$ and from 15 meters through the emitters are placed next to plants and the disposal of these rate ranges emitters of 2-16 liters/hour.

Sources of fossil fuel are being rapidly depleted and energy consumption is increasing at an exponential rate. The International Energy Outlook 2006 (IEO, 2006) projects strong growth for worldwide energy demand over the period from 2003 to 2030. The total world consumption of marketed energy expands from 421 quadrillion British thermal units (Btu) in 2003 to 563 quadrillion Btu in 2015; and then to 722 quadrillion Btu in 2030, or a $71 \%$ increase over the 2003 to 2030 period Figure 1.

Pimentel et al. [2] indicated that irrigation accounts for $13 \%$ of the agricultural energy consumption. There have been some attempts to power irrigation systems with renewable energies, but most of the resulting systems where designed for large farms and the cost for such systems is usually high. Designing successful irrigation systems powered with renewable energies for small farms depends on many factors, such as climate, crop, crop water needs, and type of irrigation system, and the kind of the crop. More accurately, it depends on the balance between the energy demand and supply. Due to the large number of factors involved in the design process of such a system, it is not easy to conduct experiments to evaluate the effect of each factor so modeling the whole process enables investigation of the effect of each factor without conducting expensive and labor intensive field experiments.

World-wide, various types and models of drip or mi- cro-irrigation have evolved. Aside from the basic technical differences, they differ in cost or affordability and in water distribution uniformity. Among the most costeffective of these models is the drip kit developed by International Development Enterprises (IDE). The drip kit consists of microtube emitters inserted through plastic tape roll laterals connected to polyethylene sub- main pipes which in turn can be connected to a drum water reservoir. The system can be operated by elevating the drum reservoir at appreciable head, thereby eliminating the need for a pumping unit. Typical operating heads of the IDE drip kits range from $1.0 \mathrm{~m}$ to $3.0 \mathrm{~m}$ [3]. This drip irrigation technology is suitable for developing countries because of its low cost and simplicity of design and installation. It has started gaining popularity in some upland watersheds in the Southeast Asian countries of the Philippines, Vietnam and Indonesia for vegetable production under agroforestry systems [4]. While distribution uniformity studies of some types of drip or trickle irrigation systems have been undertaken [5], evaluation of the performance of low-cost drip irrigation systems such as that of IDE at different heads for a given slope has not been fully explored. In fact, no rigorous study has been carried out to determine recommendable operating heads for such low-cost drip systems to generate certain levels of water distribution uniformity especially under sloping conditions. This study was conducted to determine the effect of hydraulic head and slope on the water distribution uniformity of the IDE 'Easy Drip Kit' and subsequently develop mathematical relationships to characterize the effect of slope and head on water distribution uniformity which can serve as the basis for optimizing water use efficiency and crop productivity.

Pipelines are essential for the use of drip irrigation, and they need to operate at much higher pressures (typically 1 - 2 bar for drip systems) and need to be strong enough to withstand up to twice the working pressure. The reason for this is that pressure surges which are

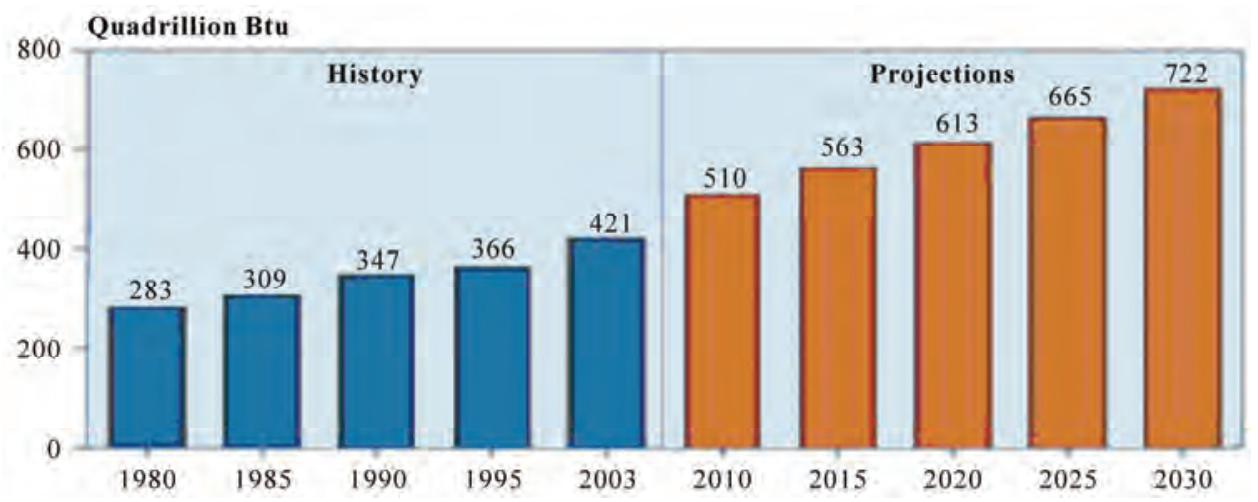

Figure 1. Global energy consumption from 1980 to 2003 and the projected consumption to 2030 in Quadrillion BTU (sources: History; International Energy Annual 2003 [1], Projection; System for the Analysis of Global Energy Markets 2006 (EIA)). 
install a pipe with the correct pressure rating to avoid the expense of repair or even replacement of a complete system. Energy is needed in pipe systems not only to pump water from the source to the pipe but also to overcome the energy losses due to friction as water flows down the pipe. If surface irrigation is used, thenproperly. Predicting head losses in pipes is not an exact science and it easy to make mistakes when calculating them. In addition, losses can increase as the pipe ages and becomes rougher inside through continued use. For these reasons the losses in the distribution system should be kept low at the design stage by choosing pipe diameters that are large enough for friction to not dominate the operation of the system at some later date. As a guideline, energy losses in the pipes should be less than $30 \%$ of the total pumping head.

Energy is another word commonly used in everyday language, but in hydraulics and irrigation it has a very specific meaning: - Energy enables useful work to be done. In irrigation, energy is needed to lift or pump water. Water energy is supplied by a pumping device driven by human or animal power, or a motor using solar, wind or fossil fuel energy.

The system of energy transfer is not perfect and energy losses occur through friction between the moving parts and are usually lost as heat energy (the human body temperature rises when work hard; an engine heats as fuel is burnt to provide power). Energy losses can be significant in pumping systems, and so can be costly in terms of fuel use [6].

Qualitative classification standards for the production of emitters, The emitter discharge rate (q) has been described by a power law, $q=k H^{x}$, where operating pressure $(\mathrm{H})$, emitter coefficient $(\mathrm{k})$, and exponent $(\mathrm{x})$ depend on emitter characteristics $[7,8]$. According to the manufacturer's coefficient of emitter variation (CVm), have been developed by ASAE. CVm values below $10 \%$ are suitable and $>20 \%$ areunacceptable [9]. The emitter discharge variation rate (qvar) should be evaluated as a design criterion in drip irrigation systems; qvar $<10 \%$ may be regarded as good and qvar $>20 \%$ as unacceptable [10,11]. Differences in emitter geometry may be caused by variation in injection pressure and heat instability during their manufacture, as well as by a heterogeneous mixture of materials used for the production [8]. Lamm et al. [12] utilizes this method in calculating the distribution uniformity of drip laterals applying wastewater from a beef lagoon. Distribution uniformities ranged from $54.3 \%$ to $97.9 \%$ for the tubing evaluated.

Only a small percentage of emitter plugging can reduce the application uniformity [13]. Talozi and Hills [14] have modeled the effects of emitter and lateral clogging on the discharge of water through all laterals.
Results show that the discharge from laterals that were simulated to be clogged decreased while laterals that were not clogged increased. In addition to decreases in discharge for emitters that were clogged, the model showed an increase of pressure at the manifold inlet. Due to the increased inlet pressure, a lower discharge rate by the pump was observed.

Berkowitz [15] observed reductions in emitter irri- gation flow ranging from 7 to $23 \%$ at five sites observed. Reductions in scouring velocities were also observed from the designed $0.6 \mathrm{~m} / \mathrm{s}(2 \mathrm{ft} / \mathrm{s})$ to $0.3 \mathrm{~m} / \mathrm{s}(1 \mathrm{ft} / \mathrm{s})$. Lines also developed some slime build-up, as reflected by the reduction in scouring velocities, but this occurred to a less degree with higher quality effluent.

In their treatments they generally used approximate friction equations such as Hazen-Williams and Scobey, neglected the variation of the velocity head along the lateral and assumed initial uniform emitter flow. Warrick and Yitayew [16] assumed a lateral with a lon- gitudinal slot and presented design charts based on spatially varied flow. The latter solution has neglected the presence of laminar flow in a considerable length of the downstream part of the lateral. Hathoot et al. [17] provided a solution based on uniform emitter discharge but took into account the change of velocity head and the variation of Reynold's number. They used the DarcyWeisbach friction equation in estimating friction losses. Hathoot et al. [18] considered individual emitters with variable outflow and presented a step by step computer program for designing either the diameter or the lateral length. In this study we considered the pressure head losses due to emitters protrusion. These losses occur when the emitter barb protrusion obstructs the water flow. Three sizes of emitter barbs were specified, small, medium and large in which the small barb has an area equal or less than $20 \mathrm{~mm}^{2}$, the medium barb has an area between $21-31 \mathrm{~mm}^{2}$ and the large one has an area equal to or more than $32 \mathrm{~mm}^{2}$ Watters et al. [19].

The objectives of the present research were:

1) Investigate emitter discharge application uniformity and its dependence on operation pressures and Laterals lengths (40, 60, and $80 \mathrm{~m}$ ).

2) To compare water and energy use efficiencies between Tow type of closed circuits (COMDIS and CTMDIS) relative to Traditional Drip System (TDIS).

\section{MATERIALS and METHODS}

\subsection{Site Location and Experiments Design}

This experiment was conducted at Irrigation Devices and Equipments Tests Laboratory, Agricultural Engineering Research Institute, Agriculture Research Center, 
Cairo, Egypt, The experimental design was randomized complete block with three replicates. Three irrigation Lateral Lines 40, 60, $80 \mathrm{~m}$ long that were installed at constant level and under Ten operating pressures $0.2,0.4$, $0.6,0.8,1.0,1.2,1.4,1.6,1.8$, and 2.0 bar for Ten minutes at each pressure. Details of the pressure and water supply control have been described by (Safi et al., 2007), to evaluate the Built-in Dripper (GR), discharge, 4 lph design emitter spacing of $30 \mathrm{~cm}$ at 1 bar nominal operating pressure in order to reach an modified way to resolve the problem of lack of pressure at the end of lateral lines in the traditional drip irrigation system.

\subsection{Field Experimental Site}

This field experiment was conducted at the Experimental Farm of Faculty of Agriculture Southern Illinois University at Carbondale (SIUC). District (latitude $37^{\circ} .73 \mathrm{~N}$, altitude $89^{\circ} .16 \mathrm{~W}$, Height about $118 \mathrm{~m} / 387$ feet above sea level), Illinois, USA.

\subsection{Drip System Components}

The components of closed circuits the drip system include, supply lines, control valves, supply and return manifolds, drip lateral lines, drip emitters, check valves and air relief valves/vacuum breakers. Figures 2, 3 show the closed circuits of drip irrigation system: 1) Closed circuit with Tow Manifold of Drip Irrigation System (CTMDIS) and 2) Closed circuit with One Manifold of Drip Irrigation System (COMDIS) while Figure 4 is Figure 3. Traditional of Drip Irrigation System (TDIS). Supply lines provide water to the supply manifolds of the system after passing through the zone control valve in systems with more than one zone. The supply manifold distributes water to the individual drip laterals within the zone. The laterals then connect to a return manifold. Along the supply and return manifold, air

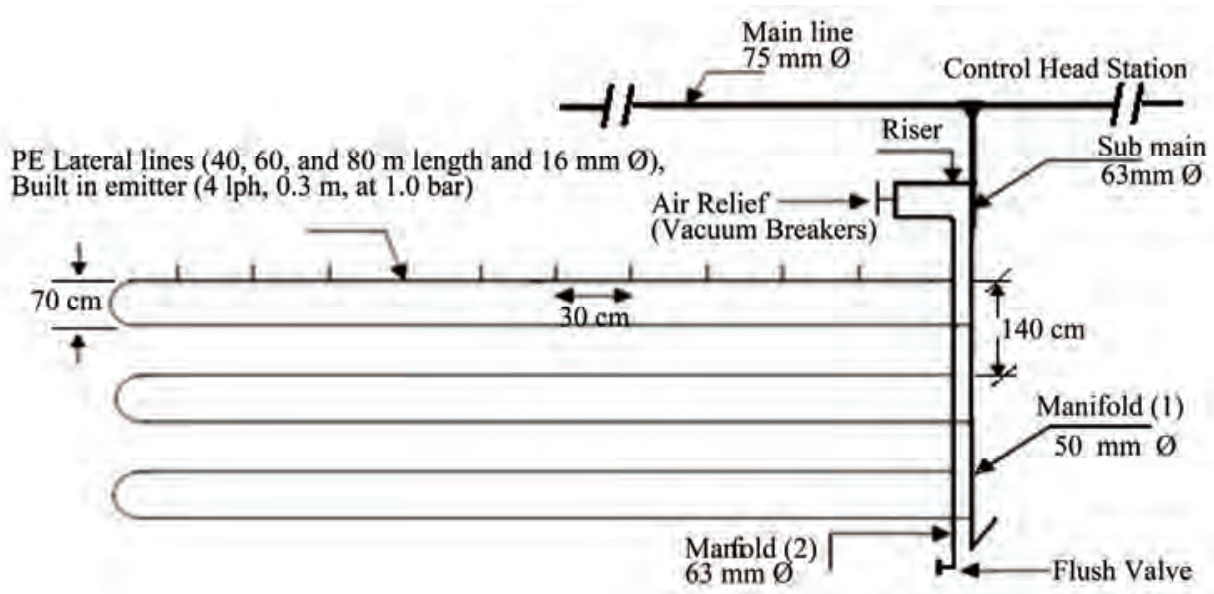

Figure 2. Layout of closed circuit with tow manifolds of drip irrigation system (CM2DIS).

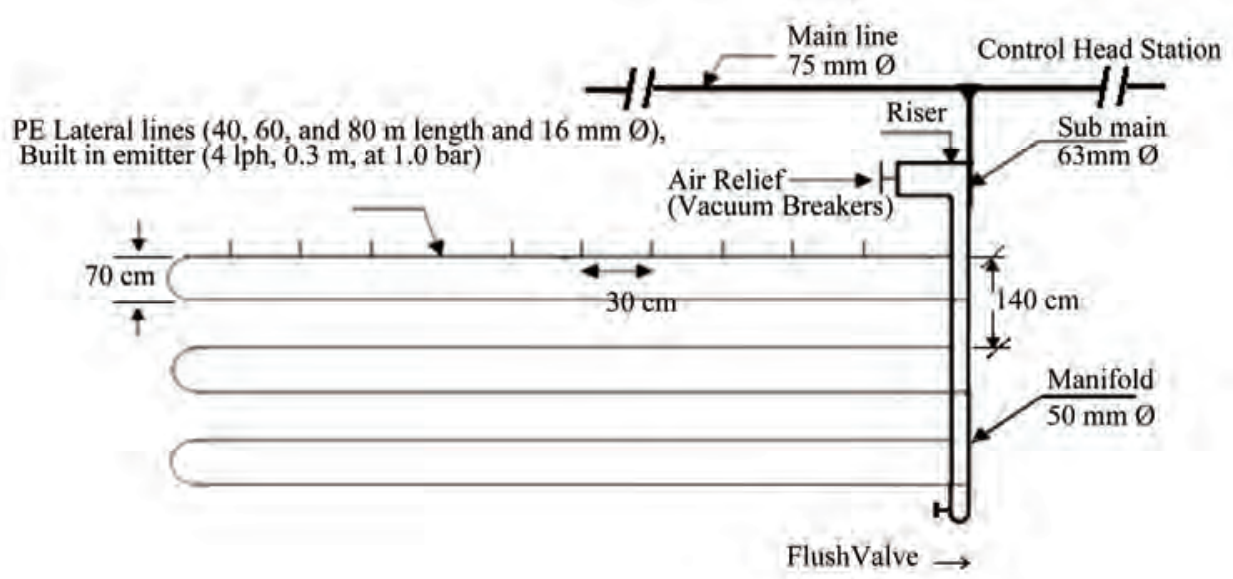

Figure 3. Layout of closed circuits with one manifold of drip irrigation system (CM1DIS). 


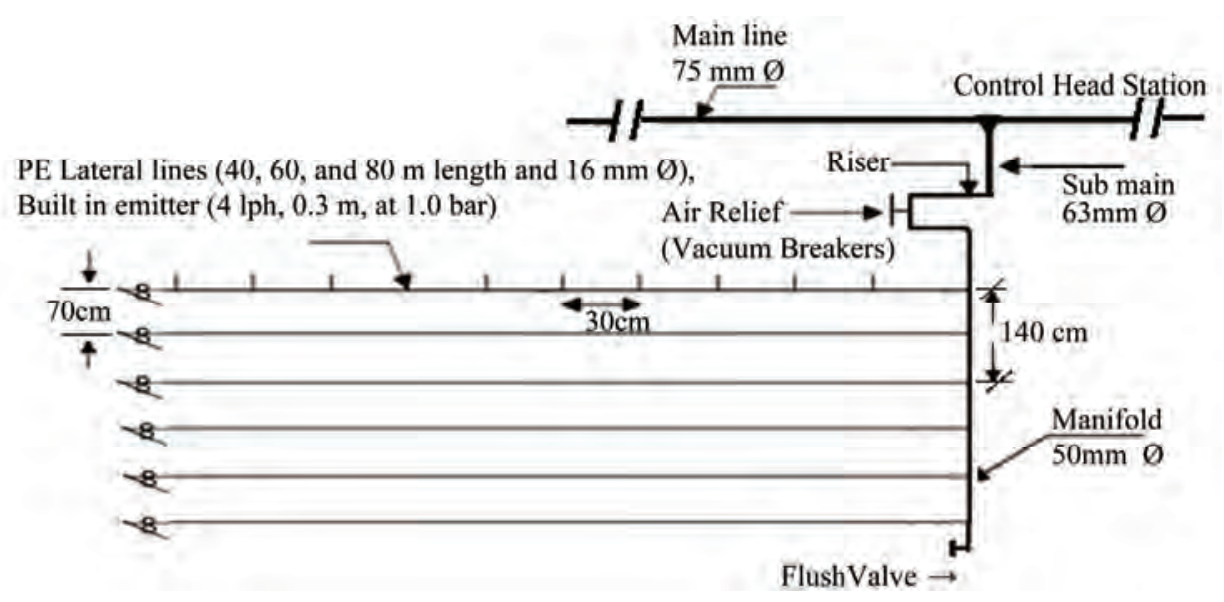

Figure 4. Layout of traditional drip irrigation system (TDIS).

relief/vacuum breakers are installed at the highest point of the manifolds to allow air to enter the system during depressurization (Netafim, 2002).

The return manifold is used during system flushing to collect water from the laterals and carry it to the return line which returns to the pretreatment device. Prior to connecting the return manifold to the return line a check valve is installed to prevent water from entering the zone during the operation of other zones.

\subsection{Head Loss in a Pipe}

The flow in the pipe throughput depends on pipe surface roughness and air layer resistance. The change of hydraulic friction coefficient values, depending on variations in Re number values. Hydraulic losses at plastic pipes might be calculated as losses at hydraulically smooth pipes, multiplied by correction coefficients that assess losses at pipe joints and air resistance.

\subsection{Head Loss in a Pipe}

The flow in the pipe throughput depends on pipe surface roughness and air layer resistance. The change of hydraulic friction coefficient values, depending on variations in Re number values. Hydraulic losses at plastic pipes might be calculated as losses at hydraulically smooth pipes, multiplied by correction coefficients that assess losses at pipe joints and air resistance.

The energy loss (or head loss) in pipes due to water flow is proportional to the pipe's length.

$$
J=\frac{\Delta H}{L}
$$

$J=$ The head loss in a pipe is usually expressed by either \% or \% (part per thousand).

Coefficient of friction is given by: Mogazhi (1998) and Bombardelli and Garcia (2003).
The head loss due to friction is calculated by HazenWilliams equation:

$$
J=1.21 \times 10^{12}\left(\frac{Q}{C}\right)^{1.852} D^{-4.87}
$$

where

$J=$ head loss is expressed by $(\mathrm{m} / 100 \mathrm{~m})$ or \%.

$Q=$ flow rate is expressed by $\mathrm{m}^{3} / \mathrm{h}$.

$D=$ Inside diameter of a pipe is expressed by $\mathrm{mm}$.

$C=$ (Hazen-Williams coefficient) smoothness (the roughness) of the internal pipe, (the range for a commercial pipe is $100-150$ ).

For polyethelene tubes when diameter $<40 \mathrm{~mm}$ and $(C=150)$. Mogazhi (1998) and Bombardelli and Garcia (2003).

Hathoot et al. (1994) for laminar flow where $R \leq$ 2000 the

$$
f=\frac{64}{R}
$$

in which $R$, Reynolds number is given by:

$$
R=\frac{V D}{v}
$$

where: $R=$ Reynolds number,

$V=$ flow velocity $(\mathrm{m} / \mathrm{s})$,

$D=$ inside diameter (m), and

$v=$ kinematic viscosity of irrigation water.

Critical velocity could be calculated by (10) and the following equations.

For turbulent flow (3000 $<R \leq 105)$ the Blasius equation can be used:

$$
f=0.316 R^{-0.25}
$$

For fully turbulent flow, $105<R<107$, recommended the following equation. 


$$
f=0.13 R^{-0.172}
$$

During design of the sewerage pipelines, partially filled pipes with free-surface flow are calculated. Hydraulic calculations are performed using the formulas applicable in the case of pressure flow, when the pipe is filled. These formulas do not take into account the resistance of air above the fluid surface, which decreases as the pipe filling is reduced. General graphs Manual of practice, 1992 are recommended for calculation of actual pipe throughput.

\subsection{Measurements of Maize (Zea Mays L.) Yield}

\section{Plant measurements:}

Components of yield were that measured grain weight $\mathrm{Kg} / \mathrm{ha}$.

\section{Water use efficiency:}

Water use efficiency is an indicator of effectiveness use of irrigation unit for increasing crop yield. Water use efficiency of seed yield was calculated from Eq.1.

\subsection{Calculating Energy Requirement}

The amount of energy needed to pump water depends on the volume of water to be pumped and the head required and can be calculated using the formula:

Water energy $(\mathrm{kWh})=$ volume of water $\left(\mathrm{m}^{3}\right) \times$ head

$$
\text { (m)/367 }
$$

Increasing either the volume of water or the head will directly increase the energy required for pumping.

\section{Energy use efficiency [5]}

Water energy $(\mathrm{kWh})=$ water power $(\mathrm{kW}) \times$ operatingtime (h)

Pumping plant efficiency $(\%)=$ (water energy/actual energy) $\times 100$

\section{Power use efficiency [5]}

Water power $(\mathrm{kW})=9.81 \times$ discharge $\left(\mathrm{m}^{3} / \mathrm{s}\right) \times$ head (m)

Pumping plant power efficiency $(\%)=($ water power/ power input) $\times 100(12)$

\section{Head loss due to friction}

The head loss due to friction was calculated using the Darcy-Weisbach equation:

$$
h=f(L / D) \times\left(v^{2} / 2 g\right)
$$

where $h=$ head loss, $\mathrm{m} ; f=$ friction factor ; $L=$ length of pipe, $\mathrm{m} ; D=$ inner diameter of pipe work, $\mathrm{m} ; \mathrm{v}=$ velocity of fluid, $\mathrm{m} / \mathrm{s} ; g=$ cceleration due to gravity, $\mathrm{m} / \mathrm{s}^{2}$.

Friction factor can be expressed as:

$$
\begin{array}{ll}
f=64 / R & \left(\text { For } R_{e} \leq 2000\right) \\
f=0.32 \times R_{e}^{-0.25} & \left(\text { For } R_{\mathrm{e}} \geq 2000\right)
\end{array}
$$

where $R_{e}=$ Reynolds' number, which can be expressed as:

$$
R_{e}=v D / \mu
$$

where $v=$ fluid velocity, $\mathrm{m} / \mathrm{sec} ; D=$ Internal pipe diameter of lateral, $\mathrm{m}$; and $v=$ kinematic viscosity of water $=1 \times 10^{-6} \mathrm{~m}^{2} / \mathrm{sec}$, at $20^{\circ} \mathrm{C}$.

Velocity $v$ can be expressed as:

$$
v=Q / A
$$

where, $Q$ = lateral flow rate (average flow rate per emitter $\times$ number of emitters), and $A=$ cross sectional area of lateral.

The calculated emission rates were then compared with the measured values to see the differences between them.

\subsection{Using Computer Program for Hydraulic Calculations}

HydroCalc irrigation system planning software is designed to help the user to define the parameters of an irrigation system. The user will be able to run the program with any suitable parameters, review the output, and change input data in order to match it to the appropriate irrigation system set up. Some parameters may be selected from a system list; whereas other are entered by the user according to their own needs so they do not conflict with the program's limitations. The software package includes an opening main window, five calculation programs, one language setting window and a database that can be modified and updated by the user.

HydroCalc includes several sub-programs as:

The Emitters program calculates the cumulative pressure loss, the average flow rate, the water flow velocity etc. in the selected emitter. It can be changed to suit the desired irrigation system parameters.

The SubMain program calculates the cumulative pressure loss and the water flow velocity in the submain distributing water pipe (single or telescopic). It changes to suit the required irrigation system parameters.

The Main Pipe program calculates the cumulative

$$
\text { WUE of seed yield }\left(\text { ton } / \mathrm{m}^{3}\right)=\frac{\text { Total seed yield }(\text { ton } / \text { fed. })}{\text { Total applied irrigation water }\left(\mathrm{m}^{3} / \text { fed. }\right)}
$$


pressure loss and the water flow velocity in the main conducting water pipe (single or telescopic). It changes to suit the required irrigation system parameters.

The Shape Wizard program helps transfer the required system parameters (Inlet Lateral Flow Rate, Minimum Head Pressure) from the Emitters program to the SubMain program.

The Valves program calculates the valve friction loss according to the given parameters.

The Shifts program calculates the irrigation rate and number of shifts needed according to the given parameters.

The Emitters program is the first application which can be used in the frame of HydroCalc software program. There are 4 basic type of emitters which can be used: Drip Line, on line, Sprinklers and Micro-Sprinklers. According to the previous selection the user can opt for a specific emitter which can be a pressure compensated or a non pressure compensated.

Each emitter has its own set of nominal flow rate values available. After the previous mentioned fields were completed, the program automatically fills the following fields: "Inside Diameter", “KD” and "Exponent”, values which cannot be changes unless the change will be made in the database. The segment length is next field in which the user must introduce a value. The end pressure represents the actual value for calculation of pressure at the furthest emitter. There are some common values for this field: around $10 \mathrm{~m}$ for drippers, around $20 \mathrm{~m}$ for mini-sprinklers, between $20-30 \mathrm{~m}$ for sprinklers and around $2 \mathrm{~m}$ when using the flushing system. There are 2 more options which can be filled before starting the computation, options which can also be used with their default values. The Flushing field can be used if the user intends to calculate a system that includes and lateral flushing. Flushing option will work only in subsequently will be used the "Emitter Line Length" calculation method. The second option is about topography. Default value is $0 \%$. Topography field has 2 sub-fields: fixed slope and changing slope. Usually the slopes values are not exceeding $10 \%$. In many cases the slope is not uniform.

\section{VALIDATION Of MEASURED DATA WITH CALCULATED DATA BY HYDROCALC}

The emission rate for 10 emitters tested for each Lateral line for lengths $(40,60$ and $80 \mathrm{~m})$ at three stages First, middle and end on the line were calculated theoretically using the following procedure.

The head loss due to friction and insertion of emitters was calculated and then the pressure head at every emitter was determined. The emission from every emitter was calculated using the characteristic equation developed for pressure head vs. discharge for each product.

\subsection{Field Experiments}

Field experiments were carried out through one successive growing season (2009/2010) under three closed circuits of drip irrigation systems, 1) One manifold for lateral lines or Closed circuits with One Manifold of Drip Irrigation System (CM1DIS); 2) Closed circuits with Two Manifolds of Drip Irrigation System (CM2DIS), and 3) Traditional Drip Irrigation System (TDIS) as a control. Lateral lines length were 40, 60 and 80 meters. PE tubes lateral lines: $16 \mathrm{~mm}$ diameter; 30 $\mathrm{cm}$ space drippers, and GR built-in drippers 4 lph for length unit when operating pressure 1 bar. Soil of experimental field represents the silty clay loam plots area has been showed in Figure 5 .

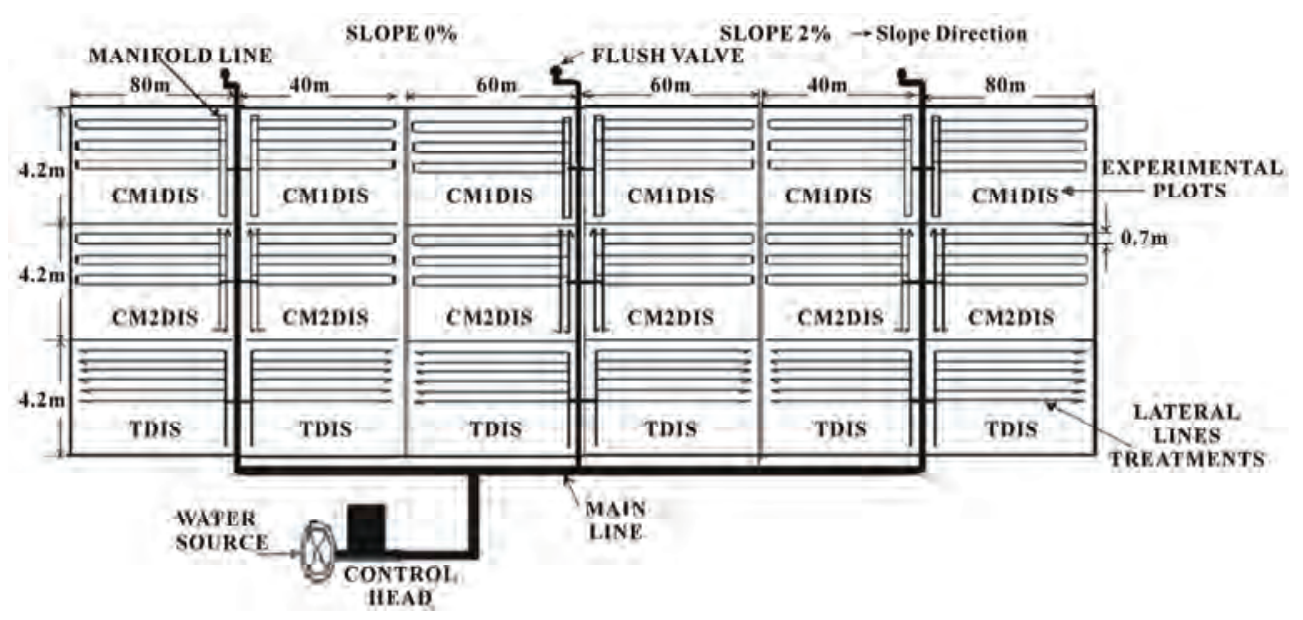

Figure 5. Layout of the experimental plots: Treatment $\mathrm{L}=40 \mathrm{~m} ; \mathrm{L}=60 \mathrm{~m}$ and $\mathrm{L}=80 \mathrm{~m}$ different Field conditions Slope $0 \%$; Slope $2 \%$ levels. 


\subsection{Soil Characteristics}

Soil particle size distribution was carried out using pipette method after Gee and Bauder (20) as shown in Table 1.

Soil $\mathrm{pH}$ and EC were measured in 1:2.5 soil water suspensions and in soil past extract, respectively according to Jackson (21) as show in Table 2.

Irrigation water analysis:

Ground water is the source of irrigation water. Irrigation water analysis is given in Table $\mathbf{3}$.

\subsection{Description of Installation}

The project was carried out during the irrigation season of the year 2009/2010 on the farm of the Experimental Farm of Faculty of Agriculture Southern Illinois University at Carbondale (SIUC) Figures 4, 6, 7. A drip irrigation system was installed on the plots and here the effect of Connection methods of closed circuits (CM1DIS; CM2DIS) and different Lateral Lengths (40, 60 and $80 \mathrm{~m}$ ) on the maize yield was studied and evaluated.

\subsection{Statistical Analysis}

All the collected data were subjected to the statistical analysis as the usual technique of analysis of variance (ANOVA) and the least significant difference (L.S.D) between systems at $1 \%$ had been done. The randomized complete block design according to Dospekhov (1984).

\section{RESULTS AND DISCUSSIONS}

\subsection{Effect of Different Operating Pressures on Drippers Change of Discharges on Lateral Lines when Slope $0 \%$.}

In Table 4 and Figures 8-10 we can be observed there was a direct relationship between the operating pressures and the average discharge of lateral lines along the lines in all cases and this is logical. When operating pressure 0.8 bar was under used CM2DIS method, the average of discharge when lateral length $40 \mathrm{~m}$ was $4.48 \mathrm{Lph}$ and when using the CM1DIS and the value of the average

Table 1. Some p hysical properties of Carbondale site.

\begin{tabular}{|c|c|c|c|c|c|c|c|c|}
\hline \multirow{2}{*}{$\begin{array}{l}\text { Sample depth, } \\
\text { cm }\end{array}$} & \multicolumn{4}{|c|}{ Particle Size Distribution, \% } & \multirow{2}{*}{ F.C., \% } & \multirow{2}{*}{ W.P., \% } & \multirow{2}{*}{ AW } & \multirow{2}{*}{$\begin{array}{c}\text { Texture } \\
\text { class }\end{array}$} \\
\hline & C. Sand & F. Sand & Silt & Clay & & & & \\
\hline 0-15 & 3.4 & 29.6 & 39.5 & 27.5 & 32.35 & 17.81 & 14.44 & S.C.L \\
\hline $15-30$ & 3.6 & 29.7 & 39.3 & 27.4 & 33.51 & 18.53 & 14.98 & S.C.L \\
\hline $30-45$ & 3.5 & 28.5 & 38.8 & 28.2 & 32.52 & 17.96 & 14.56 & S.C.L \\
\hline $45-60$ & 3.8 & 28.7 & 39.6 & 27.9 & 32.28 & 18.61 & 13.67 & S.C.L \\
\hline
\end{tabular}

S.C.L.: Silty Clay Loam

Table 2. Some chemical properties of Carbondale site.

\begin{tabular}{|c|c|c|c|c|c|c|c|c|c|c|}
\hline \multirow{2}{*}{$\begin{array}{c}\text { Sample } \\
\text { depth, cm }\end{array}$} & \multirow{2}{*}{ pH 1:2.5 } & \multirow{2}{*}{ Ec dS/m } & \multicolumn{4}{|c|}{ Soluble Cations, meq/L } & \multicolumn{4}{|c|}{ Soluble Anions, meq/L } \\
\hline & & & $\mathrm{Ca}^{++}$ & $\mathbf{M g}^{++}$ & $\mathrm{Na}^{+}$ & $\mathbf{K}^{+}$ & $\mathrm{CO}_{3}^{--}$ & $\mathrm{HCO}_{3}^{-}$ & $\mathrm{SO}_{4}^{--}$ & $\mathrm{CL}^{-}$ \\
\hline $0-15$ & 7.3 & 0.35 & 0.50 & 0.49 & 0.52 & 0.22 & 0.00 & 0.58 & 0.30 & 0.38 \\
\hline $15-30$ & 7.2 & 0.36 & 0.51 & 0.50 & 0.48 & 0.24 & 0.00 & 0.68 & 0.41 & 0.49 \\
\hline $30-45$ & 7.3 & 0.34 & 0.63 & 0.54 & 0.46 & 0.23 & 0.00 & 0.79 & 0.43 & 0.63 \\
\hline $45-60$ & 7.4 & 0.73 & 0.67 & 0.58 & 0.44 & 0.21 & 0.00 & 0.87 & 0.44 & 0.74 \\
\hline
\end{tabular}

Table 3. Some chemical data of irrigation water at Carbondale site.

\begin{tabular}{|c|c|c|c|c|c|c|c|c|c|}
\hline \multirow{2}{*}{ pH } & \multirow{2}{*}{ EC dS/m } & \multicolumn{4}{|c|}{ Soluble Cations, meq/L } & \multicolumn{3}{|c|}{ Soluble Anions, meq/L } & \multirow[t]{2}{*}{ SAR } \\
\hline & & $\mathbf{C a}^{++}$ & $\mathbf{M g}^{++}$ & $\mathrm{Na}^{+}$ & $\mathbf{K}^{+}$ & $\mathrm{HCO}_{3}^{-}$ & $\mathrm{SO}_{4}^{--}$ & $\mathrm{CL}^{--}$ & \\
\hline 7.3 & 0.37 & 1.52 & 065 & 3.19 & 0.29 & 1.80 & 0.38 & 3.10 & 3.20 \\
\hline
\end{tabular}


Table 4. Comparison between Reggrition Cooeficients $\mathrm{R}^{2}$ among the pessures and discharges values when slope $0 \%$.

\begin{tabular}{cccc}
\hline \multirow{2}{*}{$\begin{array}{c}\text { Irrigation manifold connec- } \\
\text { tions Method }\end{array}$} & \multicolumn{3}{c}{$\mathbf{R}^{2}$ Value when Lateral Length (m) } \\
\cline { 2 - 4 } CM2DIS & $\mathbf{4 0}$ & $\mathbf{6 0}$ & $\mathbf{8 0}$ \\
CM1DIS & 0.9712 & 0.9506 & 0.9397 \\
TDIS & 0.9693 & 0.9414 & 0.9368 \\
\hline
\end{tabular}

discharge was 4.20 Lph under the same length of the line.

While with the change in the operating pressure where it's increased to 1.0 bar. When the length of lateral lines was $40 \mathrm{~m}$, the average value of the discharge in this case was $4.48 \mathrm{Lph}$ under using CM2DIS While the average value of the discharge was $4.33 \mathrm{Lph}$ with using the method CM1DIS.The lateral lines at all cases of Control TDIS and lengths 60 and $80 \mathrm{~m}$ under used (CM2DIS, CM1DIS), the average value of the discharge didn't reach the standard value for this type of drippers (GR Built-in) where the standard value for this type of drippers is $4 \mathrm{Lph}$ at the operating pressure is 1.0 bar as showing below the Table 4 and Figures 8-10.

Data in Table 4 and Figures 8-10 show the relationship between different pressures (bar) and the discharge (Lph) for the closed circuits different connection methods, CM2DIS and CM1DIS with used different lateral length $40 \mathrm{~m}$ the discharge be arrived to the standard value of this dripper type when the pressure value was 0.8 bar. While with used lateral length $60 \mathrm{~m}$ under CM2DIS, the discharge be arrived to the standard value when the pressure value was 1.2 bar. By compared with TDIS when the same conditions we didn't arrived to the standard discharge at the three lateral lengths 40, 60 and $80 \mathrm{~m}$ absolutely.

According to the Regression coefficient $\mathrm{R}^{2}$ as show in Table 4 and Figures 8-10, we can note that when used the closed circuits CM2DIS the values of $\mathrm{R}^{2}$ were 0.971 , 0.950 and 0.939 with Lateral lengths 40, 60 and $80 \mathrm{~m}$

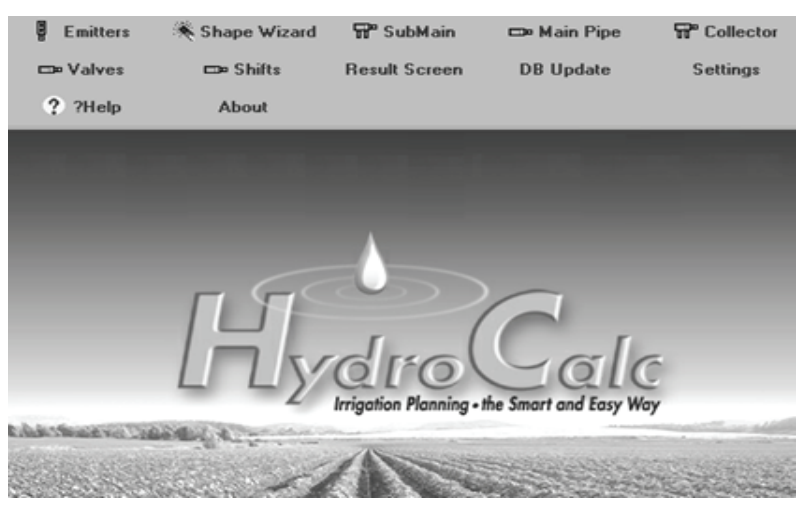

Figure 6. HydroCalc irrigation planning. respectively. Under used CM1DIS $\mathrm{R}^{2}$ values were 0.969 , 0.941 and 0.936 with lateral lengths 40,60 , and $80 \mathrm{~m}$, respectively. While under used the traditional drip system TDIS R ${ }^{2}$ values were $(0.956,0.935$, and 0.915 ) with lateral lengths 40, 60 and $80 \mathrm{~m}$, respectively. This mean that the best regression between the different pressures and discharges when used lateral length $40 \mathrm{~m}$ under CM2DIS and CM1DIS.

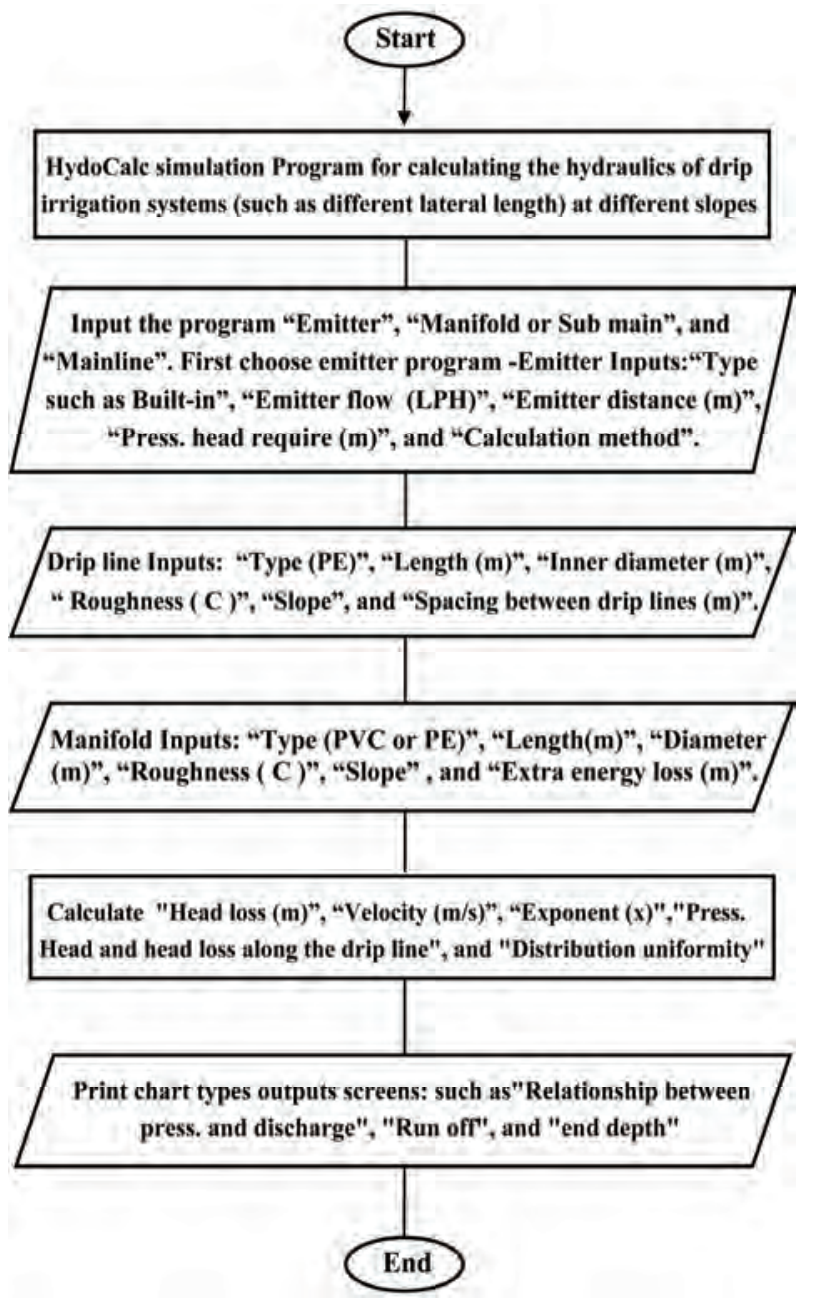

Figure 7. Flow chart components of HydroCalc simulation program for planning, design, and calculating the hydraulic analysis of drip irrigation system at different slopes or levels. 

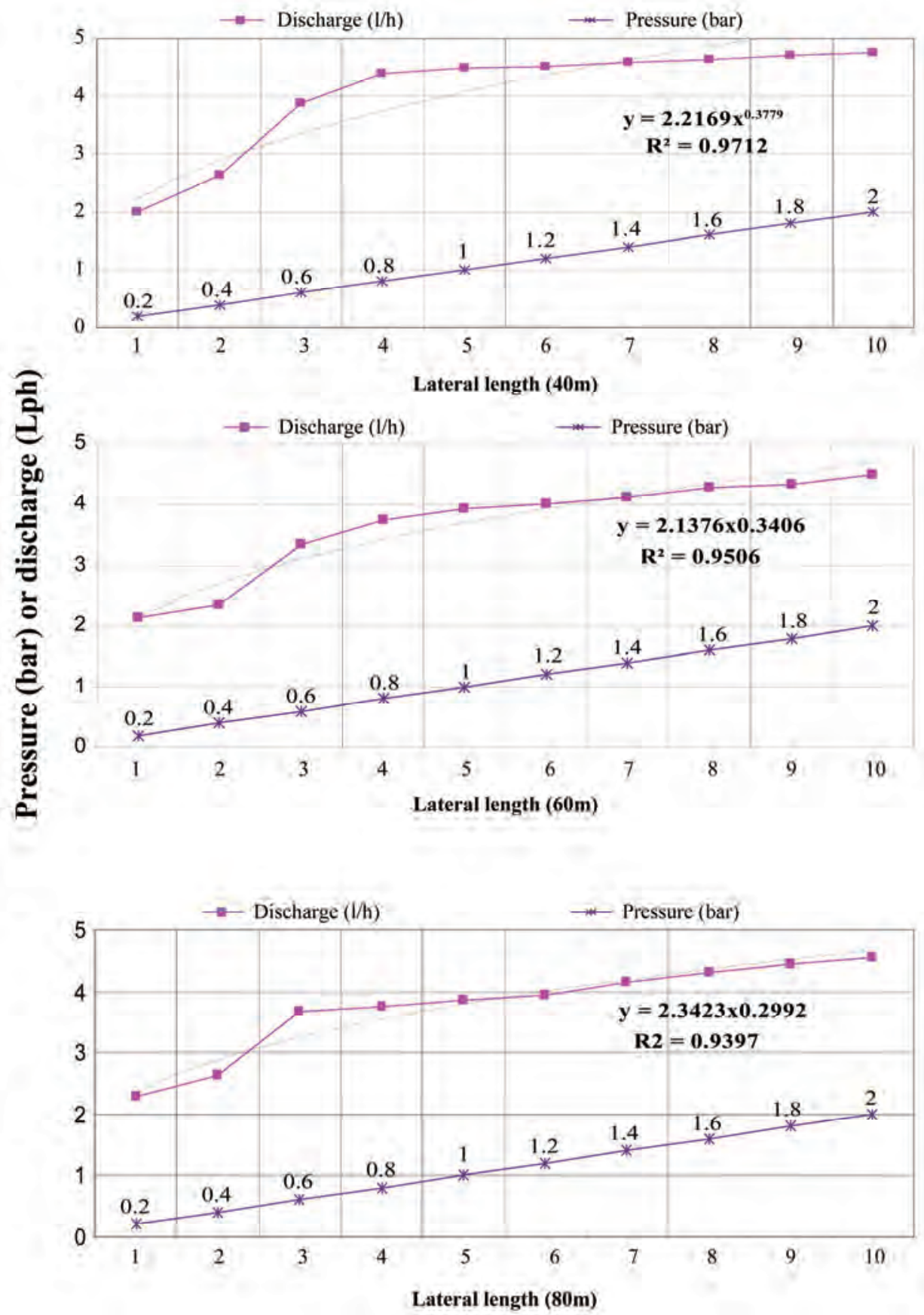

The Selected Drippers on the lateral lines of (CM2DIS)

Figure 8. Effect of different operating pressures (bar) on discharges of the closed circuits connections (CM2DIS) type when slope $0 \%$.

\subsection{Effect of Different Operating Pressures on Drippers Discharge on Lateral Lines when Slope 2\%}

In Table 5 and Figures 11-13 we can be observed there was a direct relationship between the operating pressures and the average discharge of lateral lines along the lines in all cases and this is logical. When operating pressure 0.8 bar was under used CM2DIS method, the average of discharge when lateral length $40 \mathrm{~m}$ was 4.46 

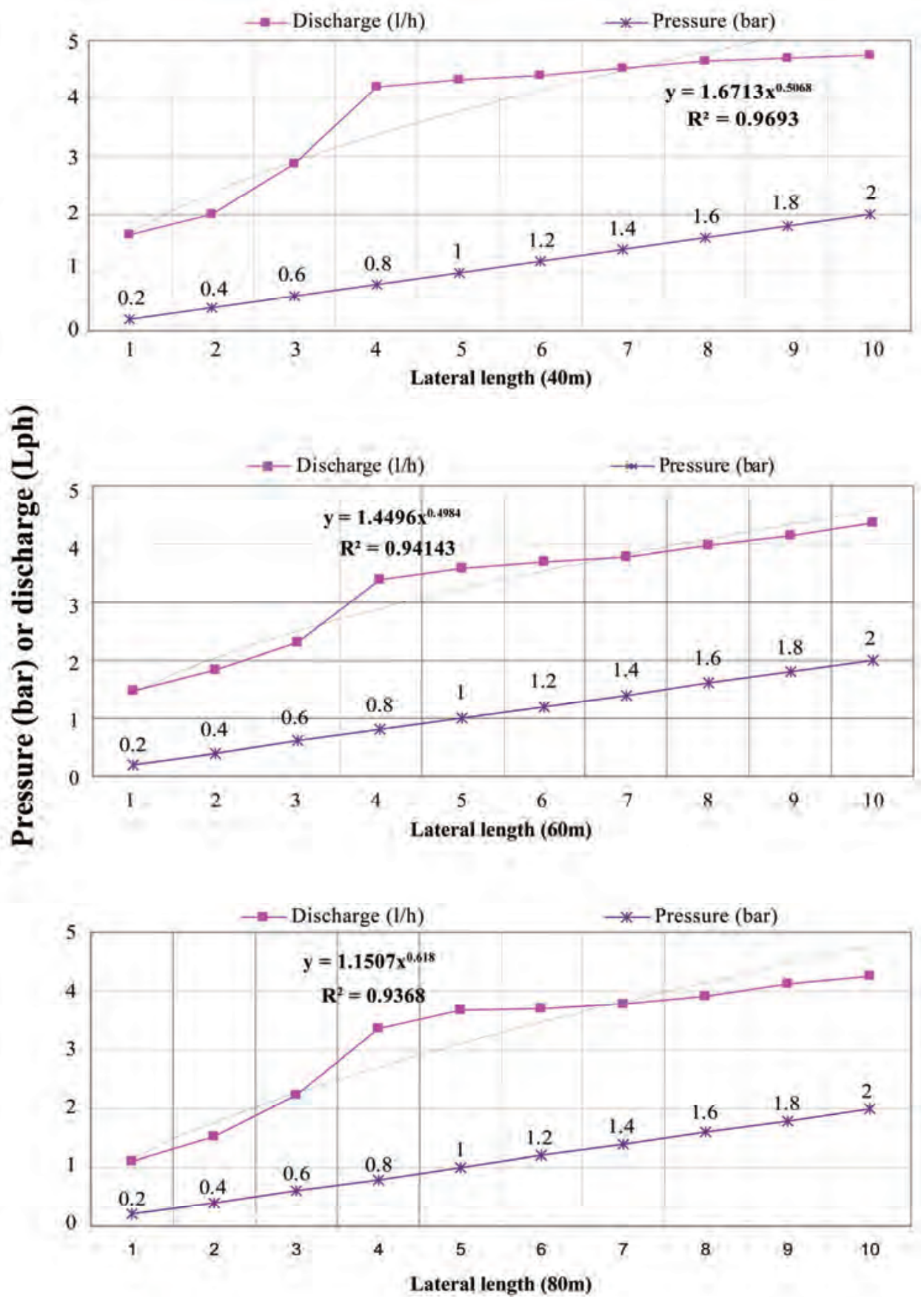

The Selected Drippers on the lateral lines of (CM1DIS)

Figure 9. Effect of different operating pressures (bar) on discharges of the closed circuits connections (cm1dis) type when slope $0 \%$.

Lph and when using the CM1DIS and the value of the average discharge was $4.32 \mathrm{Lph}$ under the same lateral line length.

While with the change in the operating pressure where it's increased to 1.0 bar. When the length of lateral lines was $40 \mathrm{~m}$, the average value of the discharge in this case was 4.56 Lph under using CM2DIS While the average value of the discharge was $4.45 \mathrm{Lph}$ with using the method CM1DIS.The lateral lines at all cases of Control TDIS and lengths 60 and $80 \mathrm{~m}$ under used (CM2DIS, CM1DIS), the average value of the discharge didn't reach the standard value for this type of drippers (GR 


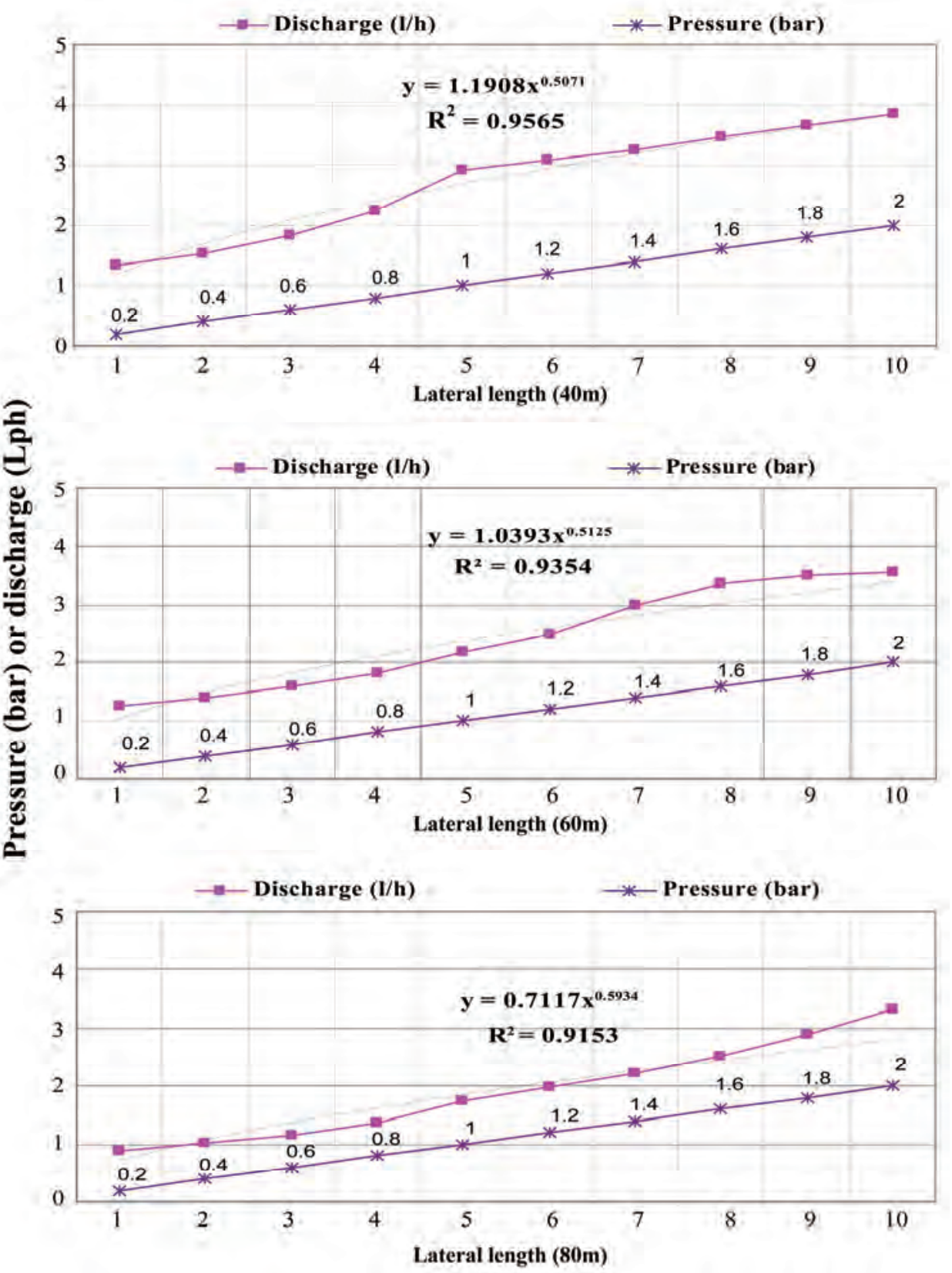

The Selected Drippers on the lateral lines of (TDIS)

Figure 10. Effect of different operating pressures (bar) on discharges of the traditional drip system (TDIS) when slope $0 \%$.

Table 5. Comparison between Reggrition Cooeficients $\mathrm{R}^{2}$ among the pessures and discharges values when slope $2 \%$.

Irrigation manifold

connections Method

CM2DIS

CM1DIS

TDIS

\begin{tabular}{ccc} 
& $\mathbf{R}^{2}$ Value when Lateral Length $(\mathbf{m})$ & \\
\hline $\mathbf{4 0}$ & $\mathbf{6 0}$ & $\mathbf{8 0}$ \\
0.9756 & 0.9618 & 0.9531 \\
0.9713 & 0.9463 & 0.9251 \\
0.9625 & 0.9552 & 0.9314
\end{tabular}




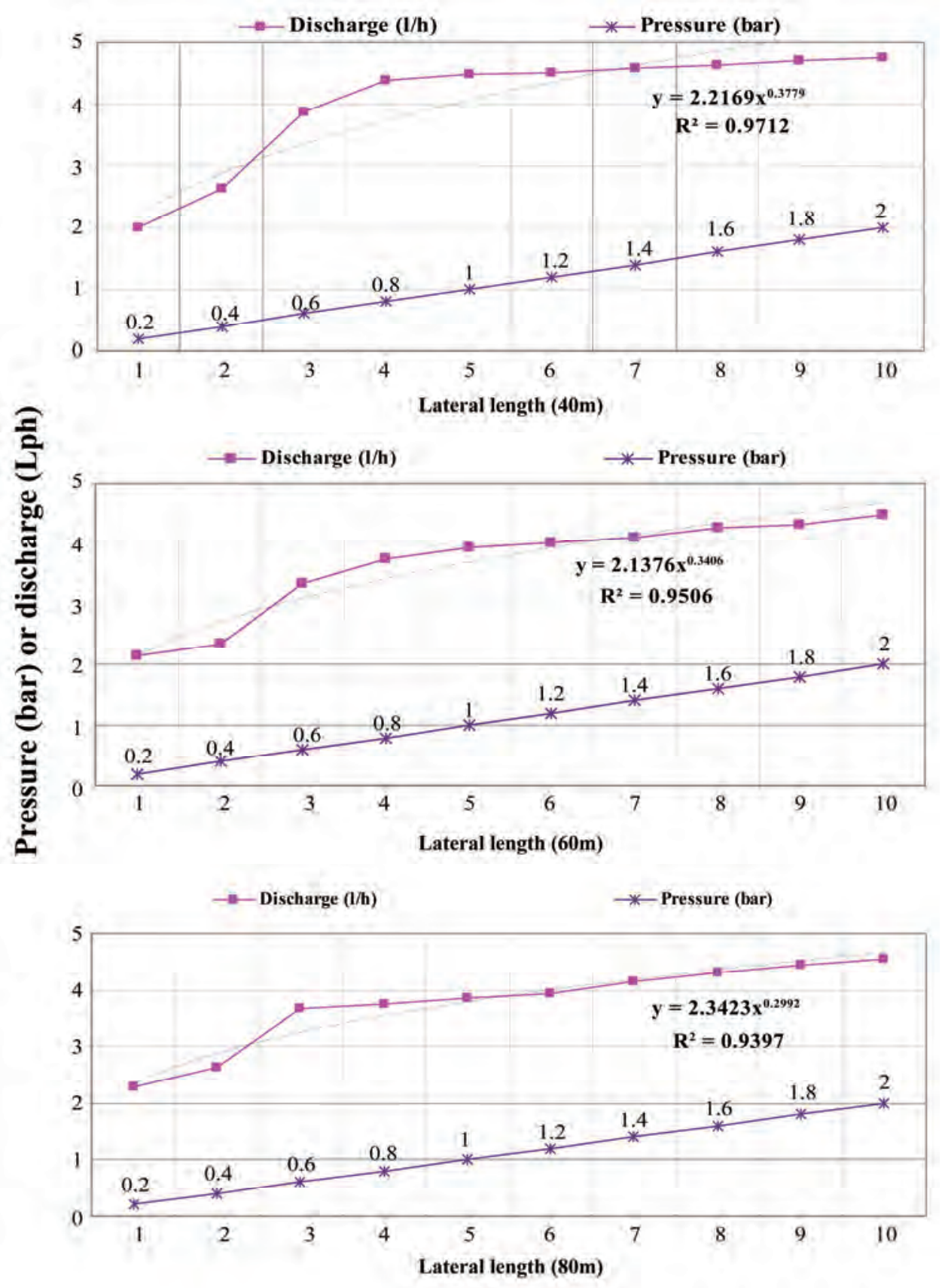

The Selected Drippers on the lateral lines of (CM2DIS)

Figure 11. Effect of different operating pressures (bar) on discharges of the closed circuits connections (CM2DIS) type when slope $2 \%$.

Built-in) where the standard value for this type of drippers is $4 \mathrm{Lph}$ at the operating pressure is 1.0 bar as showing below the Table 5 and Figures 11-13.

Data in Table 5 and Figures 11-13 show the relationship between different pressures (bar) and the discharge (Lph) for the closed circuits different connection methods, CM2DIS and CM1DIS with used different lateral length $40 \mathrm{~m}$ the discharge be arrived to the standard value of this dripper type when the pressure value was 0.8 bar. While with used lateral length $60 \mathrm{~m}$ under CM2DIS, the discharge be arrived to the standard value when the pressure value was 1.2 bar. By compared with TDIS when the same conditions we didn't arrived to the standard discharge at the three lateral lengths 40, 60 and 

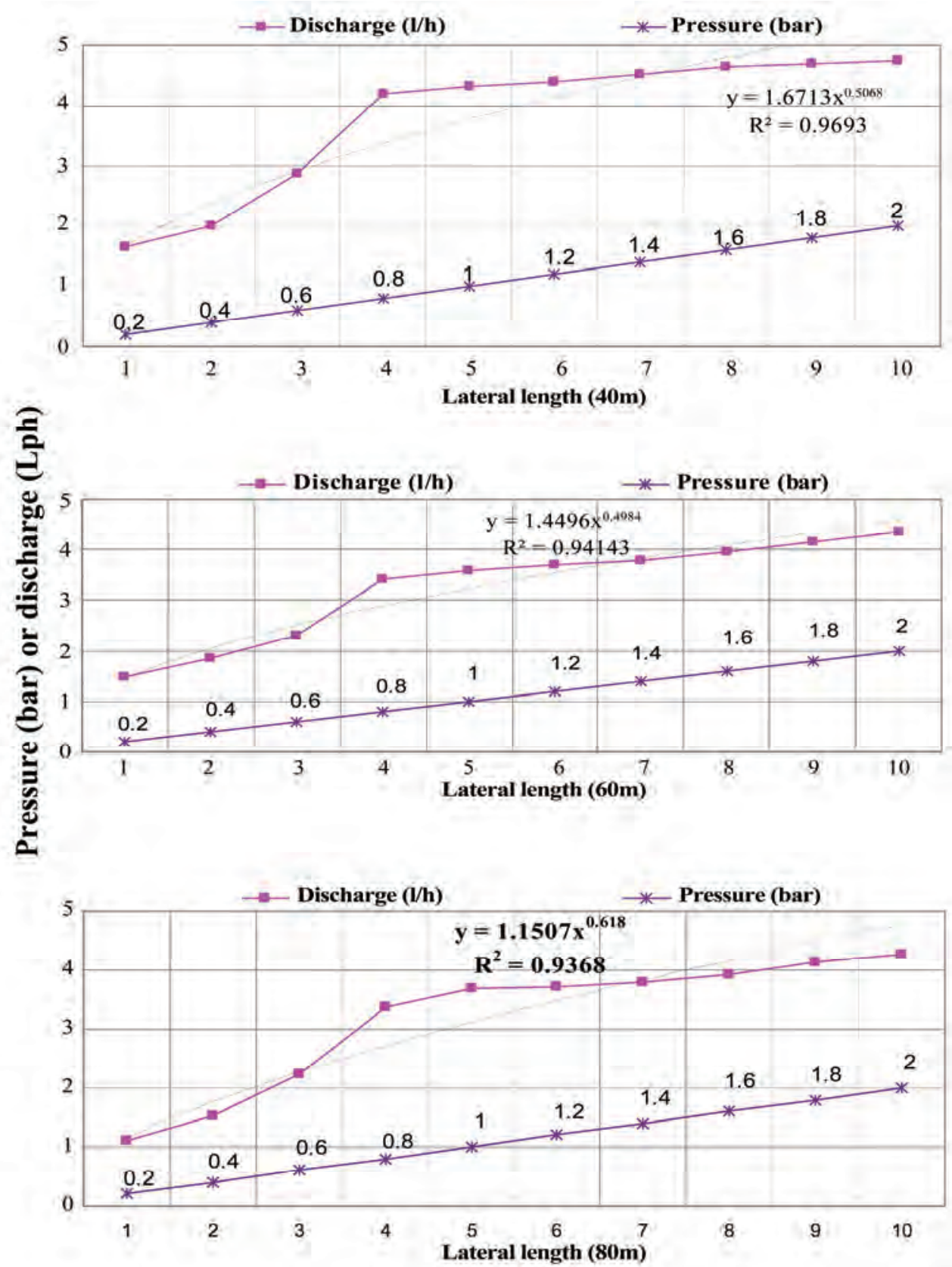

The Selected Drippers on the lateral lines of (CM2DIS)

Figure 12. Effect of different operating pressures (bar) on Discharges of the closed circuits connections (CM1DIS) type when slope $2 \%$.

$80 \mathrm{~m}$ absolutely.

According to the Regression coefficient $\mathrm{R}^{2}$ as show in Table 5 and Figures 11-13, we can note that when used the closed circuits CM2DIS the values of $\mathrm{R}^{2}$ were 0.9756, 0.9618 and 0.9531 with Lateral lengths 40 , 60 and $80 \mathrm{~m}$ respectively. Under used CM1DIS $\mathrm{R}^{2}$ values were $0.9713,0.9463$ and 0.9251 with lateral lengths 40 , 60 , and $80 \mathrm{~m}$, respectively. While under used the tradi- tional drip system TDIS R² values were (0.9625, 0.9552, and 0.9314) with lateral lengths 40, 60 and $80 \mathrm{~m}$, respectively. This mean that the best regression between the different pressures and discharges when used lateral length 40 m under CM2DIS and CM1DIS.

We can note also the pressure value of effective more (PVEM) when slope 0 and $2 \%$, its value which make large increase in the discharge and after this value the 


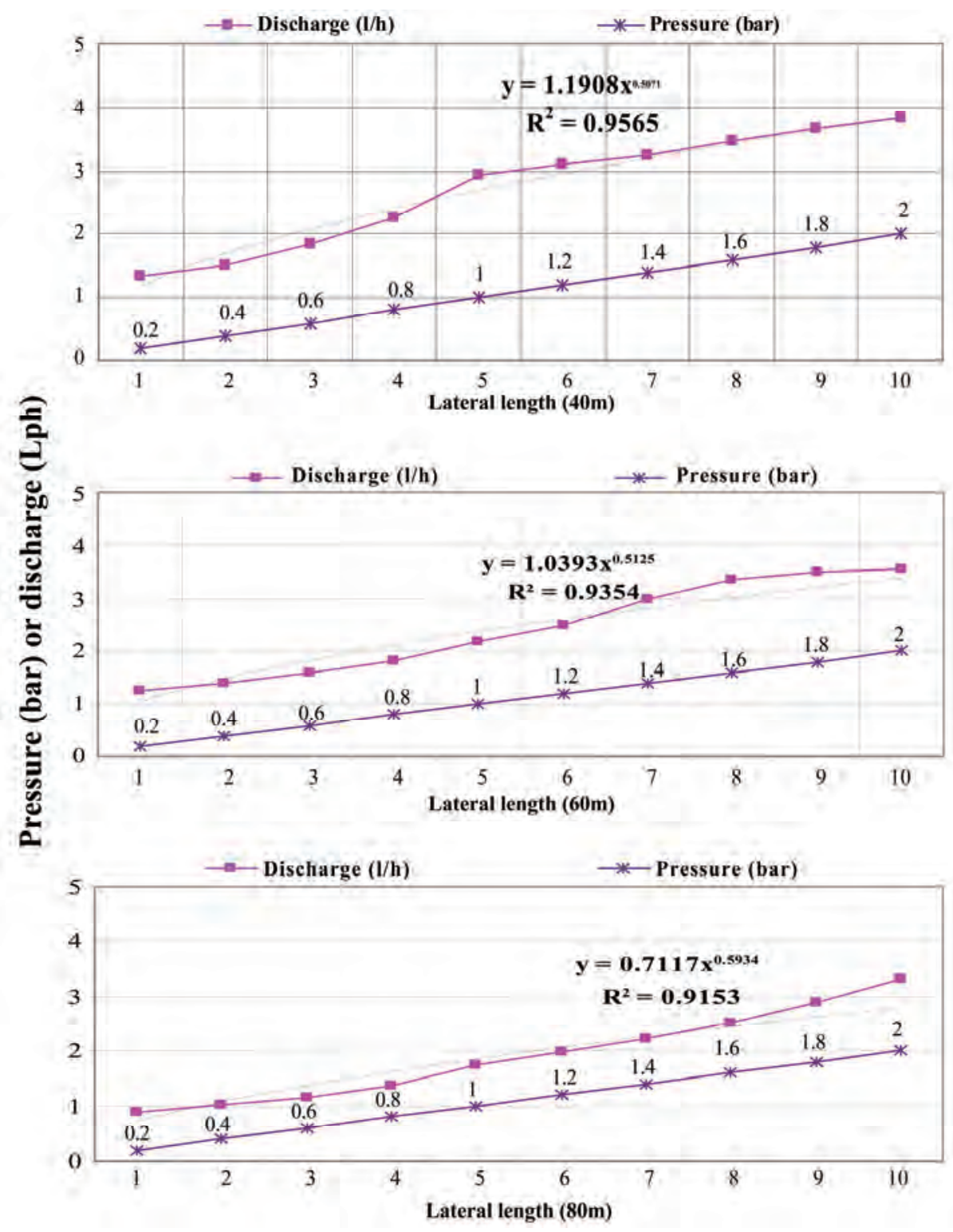

The Selected Drippers on the lateral lines of (CM2DIS)

Figure 13. Effect of different operating pressures (bar) on discharges of the traditional drip system (tdis) when slope $2 \%$.

discharge can't decrease, Absolutely. When used CM2DIS connection method at all lateral lengths 40,60 , and $80 \mathrm{~m}$ the PVEM was 0.6 bar, and under CM1DIS, with all lateral lengths treatments 40,60 , and $80 \mathrm{~m}$ the PVEM was 0.8 bar, while the traditional drip method at all lateral lengths 40,60 , and $80 \mathrm{~m}$ the PVEM was 1.0 bar.

\section{VALIDATION Of LATERAL LINES HYDRAULIC ANALYSIS by HYDROCALC SIMULATION PROGRAM WHEN SLOPE 0\% AND}

\section{$2 \%$}

\subsection{Validation of Hydrocalc Simulation Program}

The discharges and pressures head at three sites along the laterals drip line (Start, Middle and End) closed circuit connection drip irrigation systems [closed circuit with tow separates manifold lines (CM2DIS), closed circuit with one manifold line (CM1DIS), and the traditional drip system (TDIS) as a control] with different lateral lengths $(40,60$, and $80 \mathrm{~m})$ were measured under 
field conditions for two different slopes of the drip line ( 0 and $0.2 \%$ ) to validate the drip simulation program (HydroCalc Simulation program copyright 2009 developed by NETAFIM, USA), which is a computer simulation Program for planning and design of drip or sprinkler irrigation systems as used for Modification of closed circuit drip lateral lines irrigation, depends on the hydraulic equations such as, Hazen-William's Eq., Pernolli's Eq., etc. The inputs were illustrated in Table 6.

Data show in Table 6, are the inputs of HydroCalc simulation program to simulate closed circuit of drip irrigation systems under field conditions with two slopes $0 \%$ and $2 \%$ of HydroCalc simulation progrm under (CM2DIS, CM1DIS, TDIS)). The predicted outputs of HydroCalc simulation program (Exponent $(\mathrm{X})$, pressure head loss $(\mathrm{m})$, Velocity $(\mathrm{m} / \mathrm{s})$, and pressure analysis along the drippers lateral line) Figures 14-16 depend on the field measurements of pressures and discharge, as well as the predicted the field distribution uniformity.

\subsection{Predicted and Measured Head Loss Analysis along the Lateral Dripper Line of Closed Circuits under $0 \%$ Slope}

The predicted head loss analysis along the lateral drippers line had been calculated by HydroCalc simulation program for closed circuits drip irrigation systems
CM2DIS and CM1DIS compared with TDIS when slope $0 \%$ with different Lateral lengths 40,60 , and $80 \mathrm{~m}$.

Figures 14-16 and Table 7 show the relationship between predicted and measured head losses as well as regressions and correlations Under CM2DIS, CM1DIS, and TDIS methods when slope $0 \%$ level. It is obvious that the irrigation methods under study when using Lateral Length $40 \mathrm{~m}$ could be arranged in the following ascending order according the values of the predicted and measured head losses CM2DIS < CM1DIS < TDIS.

According to the Lateral Length $60 \mathrm{~m}$. the irrigation methods could put in the following ascending orders CM1DIS < CM2DIS < TDIS. While by using Lateral length $80 \mathrm{~m}$ the values of the predicted and measured head losses under irrigation methods could be arranged in the following ascending orders CM2DIS < CM1DIS < TDIS. This may be attributed to the different of numbers or how many dripper built-in with every lateral line length.

\subsection{Predicted and Measured Head Loss Analysis along the Lateral Dripper Line of Closed Circuits under 2\% Slope}

The predicted head loss analysis when slope $2 \%$ along the lateral drippers line direction had been calculated by HydroCalc simulation program for closed circuits drip

Table 6. Inputs of hydrocalc simulation program for closed circuits drip irrigation systems.

\begin{tabular}{lllll}
\hline Manifold & & Drip line & \multicolumn{2}{c}{ Emitters } \\
\hline Name & Value & Name & Value & Name \\
Pipe type: & PVC & Tubes type & PE & Emitter type \\
Pipe length: & ---- & Tubes lengths: & 40,60 , and $80 \mathrm{~m}$ & Emitter Flow (Lph) \\
Pipe diameter: & $0.05 \mathrm{~m}$ & Inner diameter & $0.0142 \mathrm{~m}$ & Euilt in \\
(C) Pipe Roughness: & 150 & (C) Pipe Roughness & 150 & Press Head Require (m) \\
Slope: & $0 \mathrm{~m} / \mathrm{m}$ & Slope & 0.0 & $0.30 \mathrm{~m}$ \\
Extra energy losses: & 0.064 & Spacing & $0.02 \mathrm{~m} / \mathrm{m}$ & Calculation Method \\
\hline
\end{tabular}

Table 7. Outputs Predicted of hydraulic analysis by hydrocalc simulation program for closed circuits drip irrigation systems with different slopes 0 and $2 \%$.

\begin{tabular}{|c|c|c|c|c|c|c|c|c|c|c|}
\hline \multirow{3}{*}{$\begin{array}{c}\text { Field } \\
\text { slope } \\
(\%)\end{array}$} & \multirow{3}{*}{$\begin{array}{l}\text { Drip line } \\
\text { length (m) }\end{array}$} & \multicolumn{9}{|c|}{ Irrigation connection method } \\
\hline & & \multicolumn{3}{|c|}{ CM2DIS } & \multicolumn{3}{|c|}{ CM1DIS } & \multicolumn{3}{|c|}{ TDIS } \\
\hline & & $\begin{array}{l}\text { Expo- } \\
\text { nent }(x)\end{array}$ & $\begin{array}{c}\text { Head loss } \\
(\mathrm{m})\end{array}$ & $\begin{array}{c}\text { Velocity } \\
(\mathrm{m} / \mathrm{s})\end{array}$ & $\begin{array}{c}\text { Expo- } \\
\text { nent (x) }\end{array}$ & $\begin{array}{c}\text { Head } \\
\text { loss (m) }\end{array}$ & $\begin{array}{c}\text { Velocity } \\
(\mathrm{m} / \mathrm{s})\end{array}$ & $\begin{array}{c}\text { Exponent } \\
(\mathrm{x})\end{array}$ & $\begin{array}{c}\text { Head } \\
\text { loss (m) }\end{array}$ & $\begin{array}{c}\text { Velocity } \\
(\mathrm{m} / \mathrm{s})\end{array}$ \\
\hline \multirow{3}{*}{$\mathbf{0}$} & 40 & 0.72 & 0.64 & 1.58 & 0.69 & 0.73 & 1.55 & 0.58 & 1.43 & 1.52 \\
\hline & 60 & 0.65 & 1.48 & 1.63 & 0.61 & 1.55 & 1.57 & 0.55 & 2.35 & 1.64 \\
\hline & 80 & 0.58 & 3.00 & 1.92 & 0.52 & 3.11 & 1.88 & 0.53 & 3.58 & 2.18 \\
\hline \multirow{3}{*}{2} & 40 & 0.76 & 0.45 & 1.51 & 0.71 & 0.76 & 1.51 & 0.63 & 1.38 & 1.51 \\
\hline & 60 & 0.68 & 1.34 & 1.57 & 0.64 & 1.55 & 1.55 & 0.59 & 2.26 & 1.62 \\
\hline & 80 & 0.61 & 2.92 & 1.89 & 0.58 & 3.00 & 1.74 & 0.55 & 3.37 & 1.97 \\
\hline
\end{tabular}



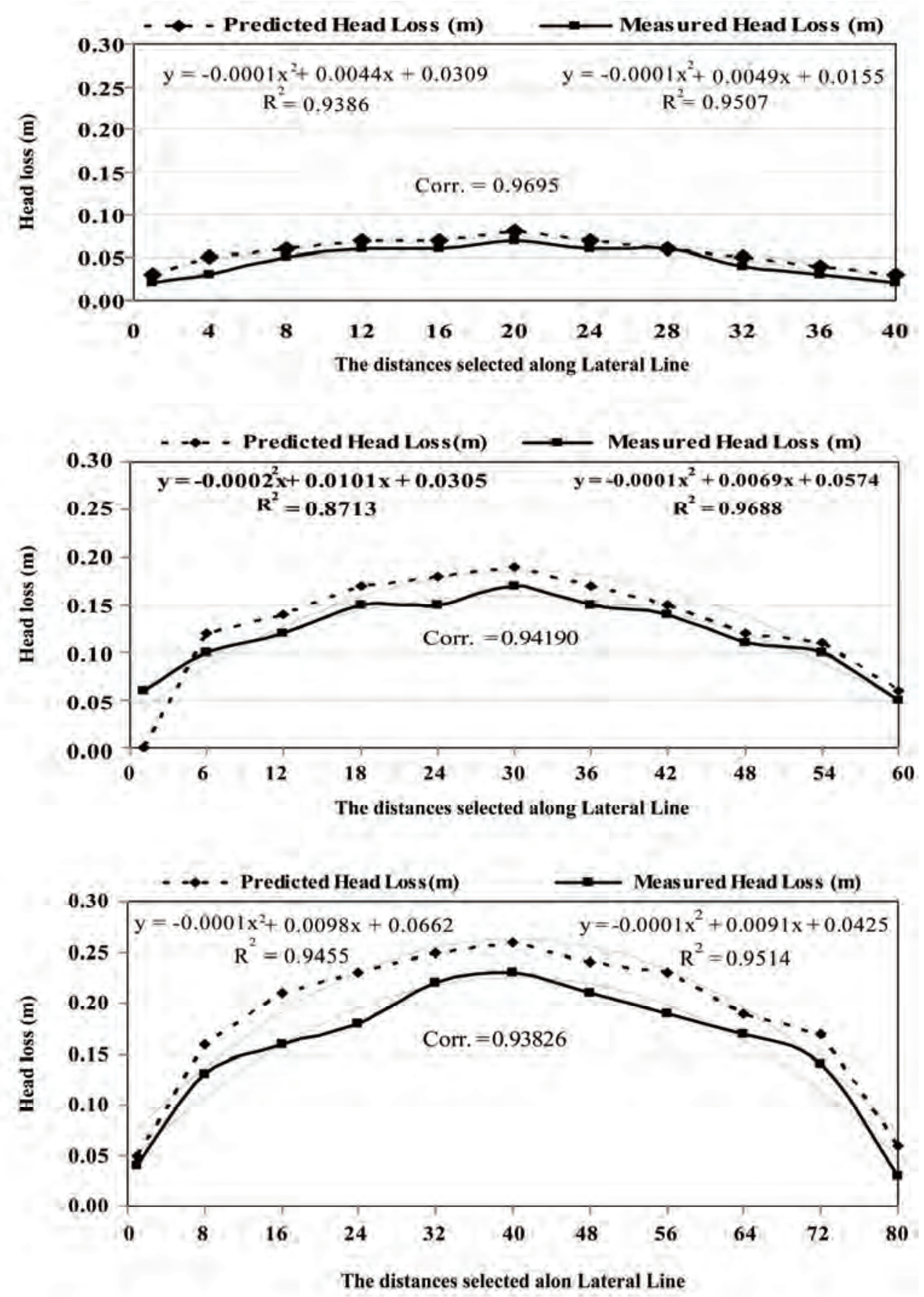

Figure 14. The relationship between different lateral lengths 40, 60; $80 \mathrm{~m}$ and both of predicted and measured head loss when slope $0 \%$ with closed circuits CM2DIS method.

irrigation systems CM2DIS and CM1DIS compared with TDIS with different Lateral lengths 40, 60, and $80 \mathrm{~m}$, as show Figures 17-19 and Table 7 shows the relationship between predicted and measured head losses as well as regressions and correlations Under irrigation methods under study when slope $2 \%$ level.

Methods could put in the following ascending orders
CM2DIS < CM1DIS < TDIS.

Irrigation methods under study when using Lateral Length $60 \mathrm{~m}$ could be arranged in the following ascending order according the values of the predicted and measured head losses CM1DIS < CM2DIS < TDIS.

While by using Lateral length $80 \mathrm{~m}$ the values of the predicted and measured head losses under irrigation 

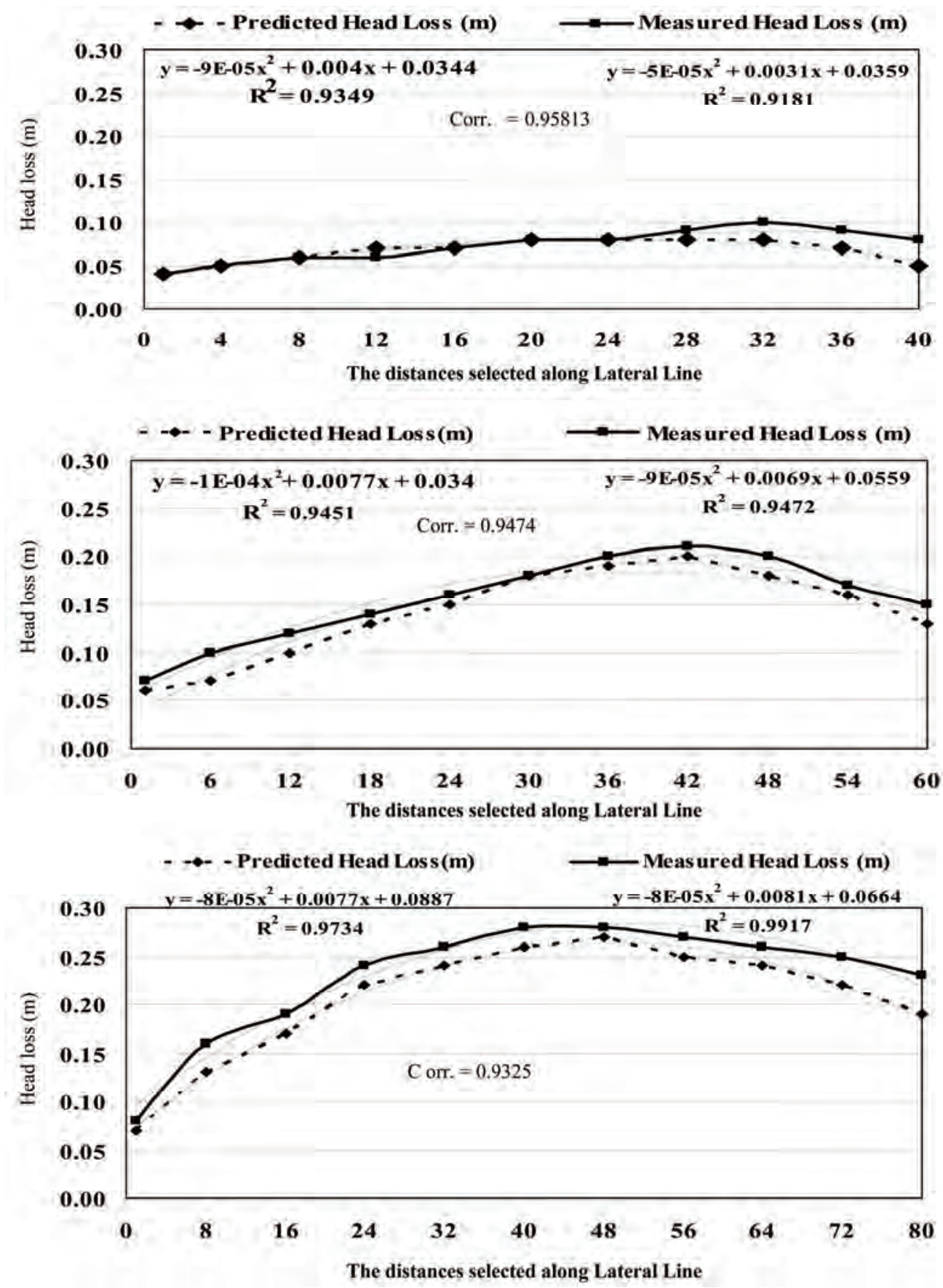

Figure 15. The relationship between different lateral lengths 40,60; $80 \mathrm{~m}$ and both of predicted and measured head loss when slope $0 \%$ with closed circuits CM1DIS method.

methods could be arranged in the following ascending orders CM2DIS < CM1DIS < TDIS. This may be attributed to the different of numbers or how many dripper built-in with every lateral line length. The regression $\left(\mathrm{R}^{2}\right)$ and correlation (Corr.) had been obtained for comparing the predicted and measured head loss along the lateral lines of all the closed circuits methods. Generally, the values of regression and correlation analysis were (>
0.90 ) were obtained by using 0 and $2 \%$ field slope and 40,60 , and $80 \mathrm{~m}$ lengths (experimental conditions) for all closed circuits.

\subsection{Energy Saving Comparison between All Closed Circuits under Study}

It is worthy to mention that the data in Table 8 indicate 

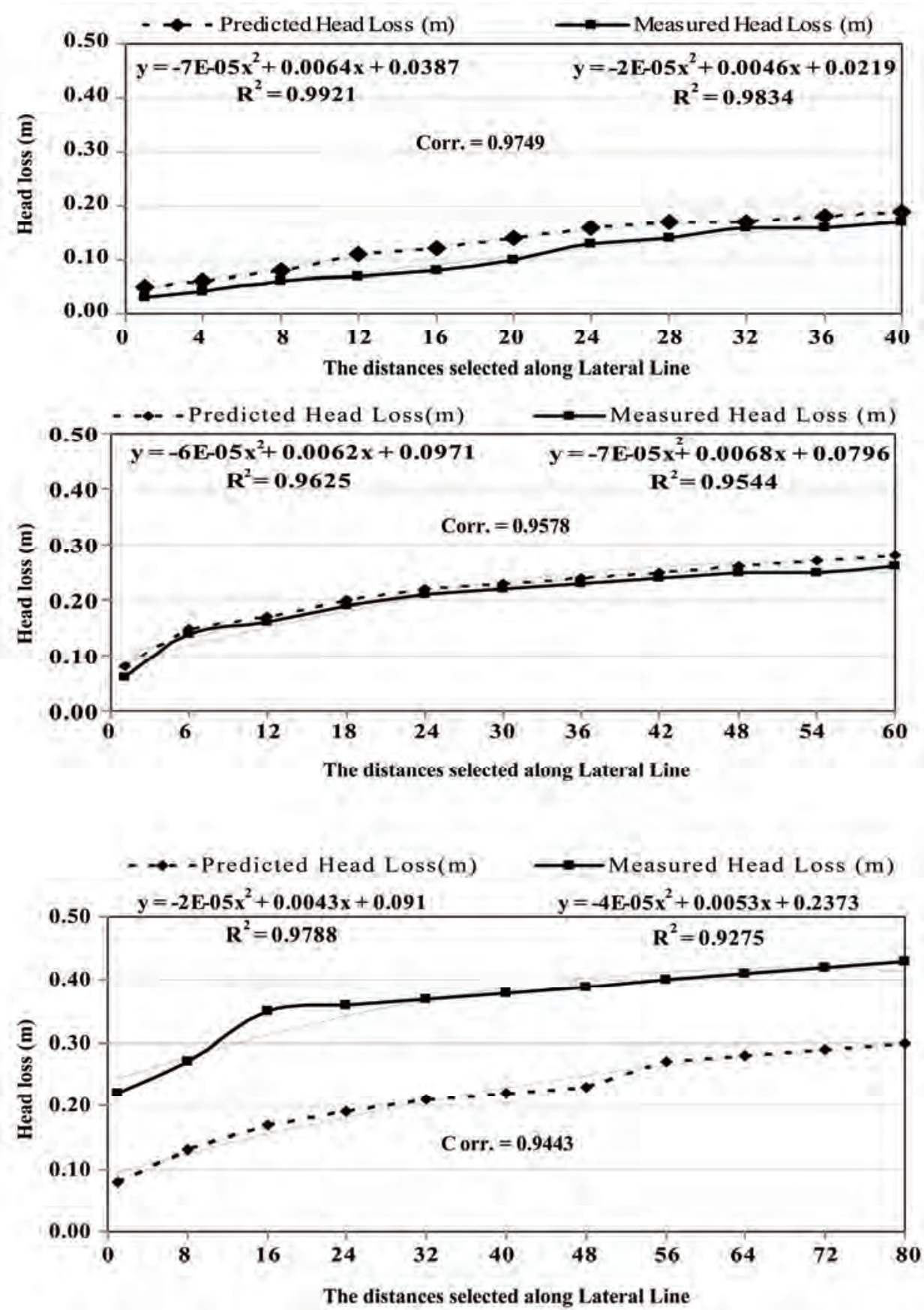

Figure 16. The relationship between different lateral lengths 40,60; $80 \mathrm{~m}$ and both of predicted and measured head loss when slope $0 \%$ with closed circuits TDIS method.

to that the highest values of energy saving were when using slope $2 \%$ level under CM2DIS were (31.57; 33.14 and 34.25\%), then CM1DIS (30.15; 28.98 and 27.53\%) with used Lateral lengths (40; 60 and $80 \mathrm{~m}$ ), respectively comparing by TDIS.

While the energy saving values with slope $0 \%$ were under CM2DIS (32.27; 33.21 and 34.37\%), and under CM1DIS (30.84; 28.96 and 27.45\%) when using lateral lengths (40; 60 and $80 \mathrm{~m}$ ), respectively relative to traditional drip system TDIS as a control.

\section{WATER USE EFFICIENCY (WUE)}

Data in Tables 9, 10 show that, Water Use Efficiency (WUE) when level slope $0 \%$ under CM2DIS were 1.67 , 1.18 , and $0.87 \mathrm{~kg} / \mathrm{m}^{3}$ compared to $1.65,1.16$, and 0.86 

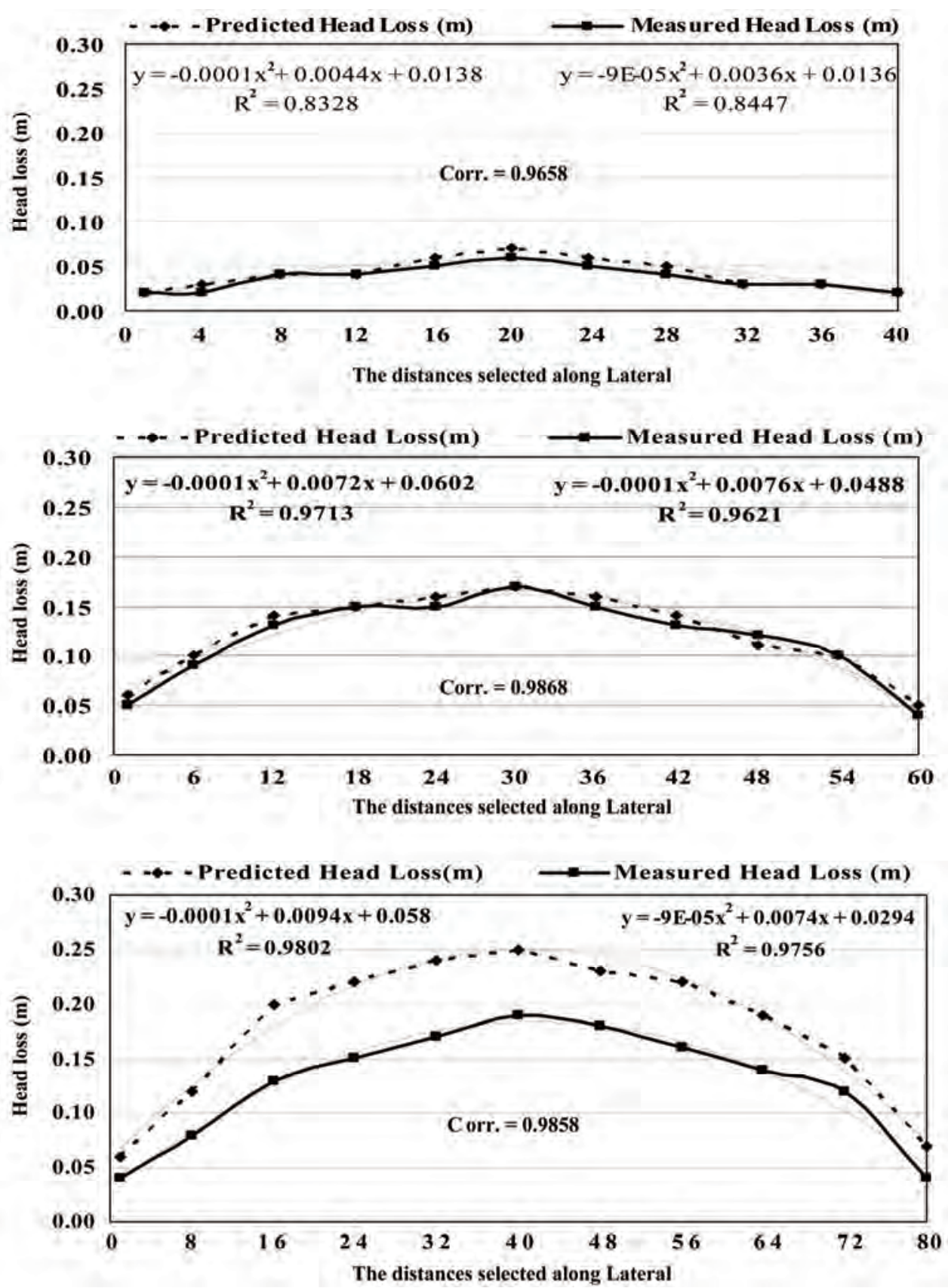

Figure 17. The relationship between different lateral lengths 40,60; $80 \mathrm{~m}$ and both of predicted and measured head loss when slope $2 \%$ with closed circuits CM2DIS method.

$\mathrm{kg} / \mathrm{m}^{3}$ with CM1DIS and $1.35,1.04$, and $0.75 \mathrm{~kg} / \mathrm{m}^{3}$ with TDIS whereas with level slope $2 \%$ when using CM2DIS were $1.76,1.29$, and $0.84 \mathrm{~kg} / \mathrm{m}^{3}$ compared to $1.77,1.30$, and $0.87 \mathrm{~kg} / \mathrm{m}^{3}$ with CM1DIS and $1.41,1.12$, and 0.76 $\mathrm{kg} / \mathrm{m}^{3}$ (for lateral lengths 40,60 , and 80 meters respectively).

\section{CONCLUSIONS}

It could be concluded that:
The pressure value of effective more when slope $0 \%$ and $2 \%$ (PVEM) it's value which make large increase in the discharge and after this value the discharge can't decrease, Absolutely. When used CM2DIS connection method at all lateral lengths 40,60 , and $80 \mathrm{~m}$ the PVEM was 0.6 bar, and under CM1DIS, with all lateral lengths treatments 40,60 , and $80 \mathrm{~m}$ the PVEM was $0.8 \mathrm{bar}$, while the traditional drip method at all lateral lengths 40 , 60 , and $80 \mathrm{~m}$ the PVEM was 1.0 bar. 

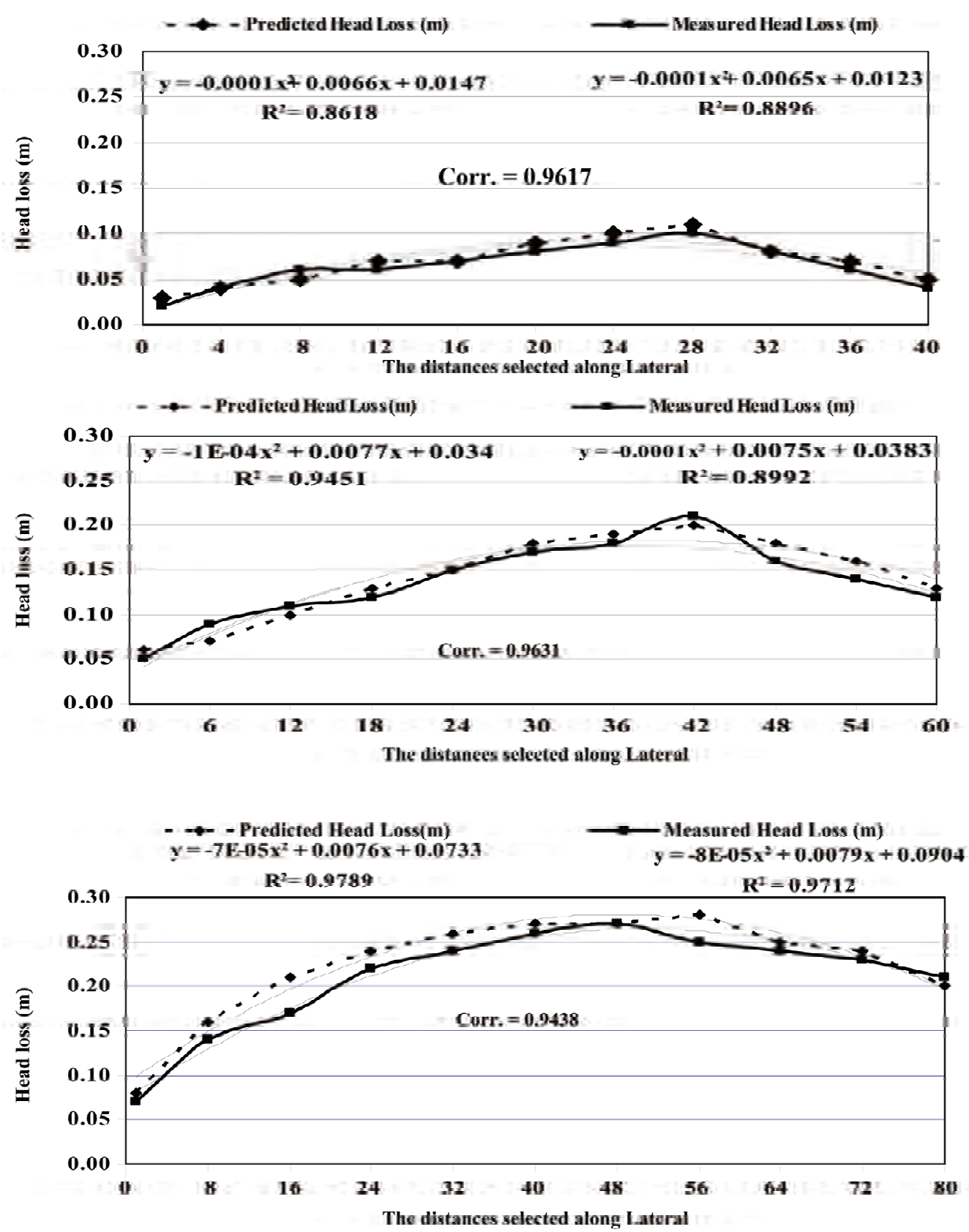

Figure 18. The relationship between different lateral lengths 40,60; $80 \mathrm{~m}$ and both of predicted and measured head loss when slope $2 \%$ with closed circuits CM1DIS method.

Irrigation systems at $40,60,80 \mathrm{~m}$ could be arranged according to Energy Use Efficiency (EUE), Water Use Efficiency (WUE), in the following ascending order: TDIS < CM1DIS < CM2DIS. Irrigation systems at 40, $60,80 \mathrm{~m}$ could be arranged according to friction losses of lateral lines in the following ascending order: CM2DIS < CM1DIS < TDIS.

Under $0 \%$ level slope in when using CM2DIS the increases percentage of Energy Use Efficiency (EUE) were $32.27,33.21$, and $34.37 \%$ while with CM1DIS were 30.84 , 28.96, and $27.45 \%$ whereas under slope $2 \%$ were with CM2DIS 31.57, 33.14, and 34.25 on the other hand CM1DIS were 30.15, 28.98, and 27.53 under lateral lengths 40,60 and $80 \mathrm{~m}$ respectively relative to TDIS.

Water Use Efficiency (WUE) when level slope 0\% under CM2DIS were $1.67,1.18$, and $0.87 \mathrm{~kg} / \mathrm{m}^{3} \mathrm{com}$ pared to $1.65,1.16$, and $0.86 \mathrm{~kg} / \mathrm{m}^{3}$ with CM1DIS and $1.35,1.04$, and $0.75 \mathrm{~kg} / \mathrm{m}^{3}$ with TDIS whereas with level slope $2 \%$ when using CM2DIS were $1.76,1.29$, 

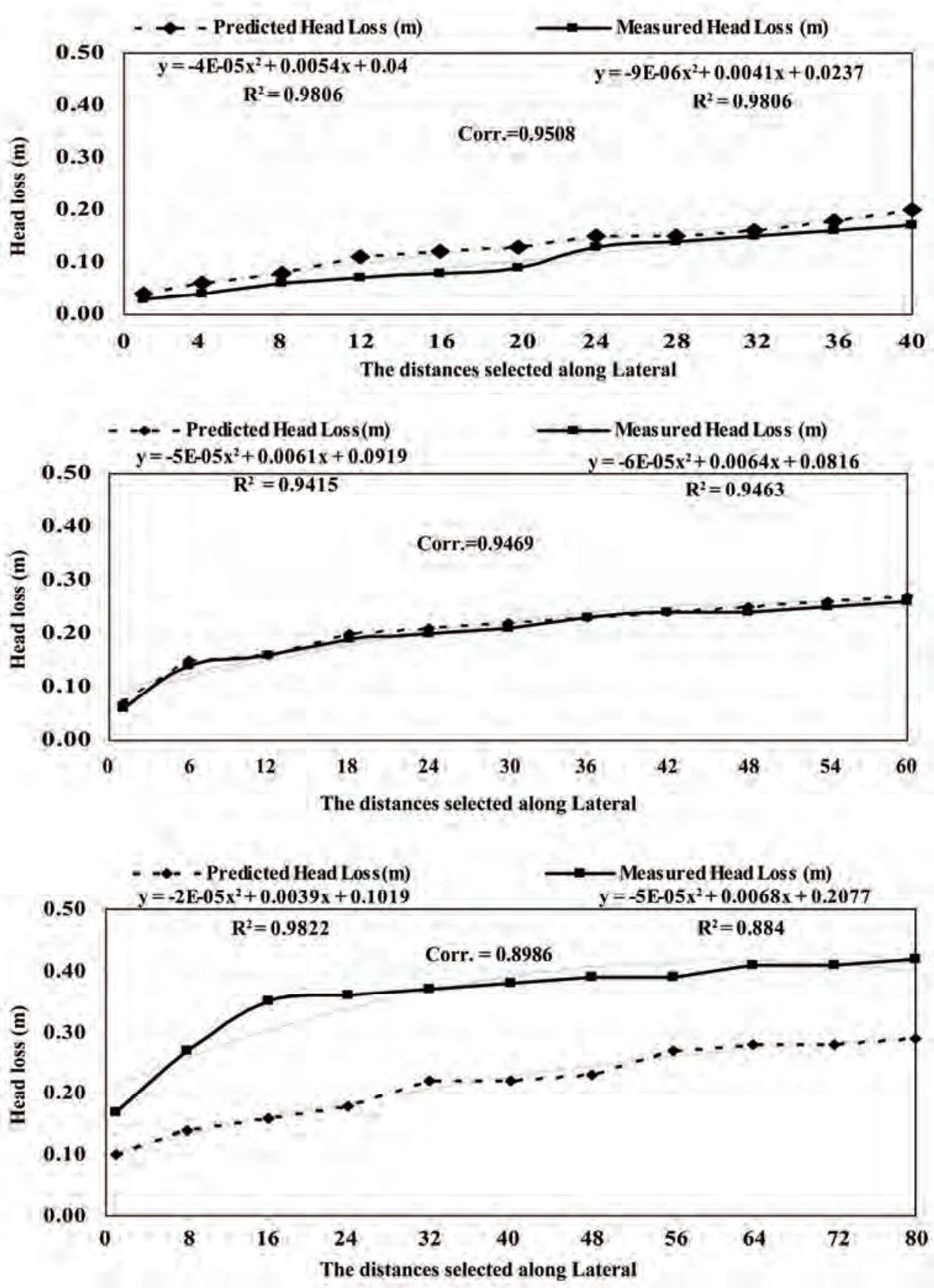

Figure 19. The relationship between different lateral lengths 40, 60; $80 \mathrm{~m}$ and both of predicted and measured head loss when slope $2 \%$ with closed circuits TDIS method.

Table 8. Energy saving of closed circuit modified methods had been calculated by comparing with TDIS.

\begin{tabular}{cccccccc}
\hline & \multicolumn{7}{c}{ Energy saving (\%) of irrigation method } \\
\cline { 2 - 8 } Field slope (\%) & $\mathbf{4 0}$ & CM2DIS & $\mathbf{6 0}$ & $\mathbf{8 0}$ & $\mathbf{4 0}$ & CM1DIS \\
& 32.27 & 33.21 & 34.37 & 30.84 & $\mathbf{6 0}$ & $\mathbf{8 0}$ \\
$\mathbf{0}$ & 31.57 & 33.14 & 34.25 & 30.15 & 28.96 & 27.45 & 27.93 \\
\hline
\end{tabular}


Table 9. Effect of closed circuits drip irrigation methods on WUE and EUE when slope level 0\%.

\begin{tabular}{|c|c|c|c|c|c|c|c|c|}
\hline $\begin{array}{c}\text { Irrigation } \\
\text { methods }\end{array}$ & $\begin{array}{c}\text { Lateral } \\
\text { Lengths m }\end{array}$ & $\begin{array}{c}\text { Applied } \\
\text { water } \mathbf{m}^{3} / \mathbf{h a}\end{array}$ & Yield kg/ha & $\begin{array}{c}\text { WUE } \\
\left(\mathrm{kg} / \mathrm{m}^{3}\right)\end{array}$ & $\begin{array}{c}\text { Water } \\
\text { Demand }\left(\mathrm{m}^{3}\right)\end{array}$ & $\begin{array}{c}\text { Actual } \\
\text { Energy (kwh) }\end{array}$ & $\begin{array}{c}\text { Water } \\
\text { Energy (kwh) }\end{array}$ & EUE \% \\
\hline \multirow{3}{*}{ CM2DIS } & 40 & 7725.16 & 12885.27 & 1.67 & 9879.73 & 255.74 & 199.97 & 78.19 \\
\hline & 60 & 10338.91 & 12235.62 & 1.18 & 13583.81 & 322.01 & 245.09 & 76.11 \\
\hline & 80 & 13757.42 & 12023.18 & 0.87 & 18686.05 & 366.59 & 269.90 & 73.62 \\
\hline \multirow{3}{*}{ CM1DIS } & 40 & 7638.29 & 12623.69 & 1.65 & 9973.74 & 250.02 & 191.48 & 76.58 \\
\hline & 60 & 10382.71 & 12015.51 & 1.16 & 14509.10 & 328.13 & 234.81 & 71.56 \\
\hline & 80 & 13782.14 & 11871.72 & 0.86 & 20693.90 & 388.50 & 258.74 & 66.60 \\
\hline \multirow{3}{*}{ TDIS } & 40 & 8932.25 & 12029.28 & 1.35 & 16865.39 & 407.16 & 215.64 & 52.96 \\
\hline & 60 & 10652.88 & 11034.12 & 1.04 & 20954.56 & 444.78 & 226.12 & 50.84 \\
\hline & 80 & 15212.70 & 11429.77 & 0.75 & 31484.54 & 514.73 & 248.71 & 48.32 \\
\hline
\end{tabular}

Table 10. Effect of closed circuits drip irrigation methods on WUE and EUE when slope level 2\%.

\begin{tabular}{|c|c|c|c|c|c|c|c|c|}
\hline $\begin{array}{l}\text { Irrigation } \\
\text { methods }\end{array}$ & $\begin{array}{c}\text { Lateral } \\
\text { Lengths m }\end{array}$ & $\begin{array}{c}\text { Applied water } \\
\mathrm{m}^{3} / \mathrm{ha}\end{array}$ & Yield kg/ha & $\begin{array}{c}\text { WUE } \\
\left(\mathrm{kg} / \mathrm{m}^{3}\right)\end{array}$ & $\begin{array}{c}\text { Water Demand } \\
\left(\mathbf{m}^{3}\right)\end{array}$ & $\begin{array}{c}\text { Actual Energy } \\
\text { (kwh) }\end{array}$ & $\begin{array}{c}\text { Water Energy } \\
\text { (kwh) }\end{array}$ & EUE \% \\
\hline & 40 & 7488.73 & 13152.71 & 1.76 & 9558.78 & 250.04 & 195.89 & 78.34 \\
\hline \multirow[t]{3}{*}{ CM2DIS } & 60 & 9823.52 & 12641.23 & 1.29 & 12872.84 & 305.86 & 233.41 & 76.31 \\
\hline & 80 & 14893.68 & 12551.34 & 0.84 & 20172.39 & 390.26 & 288.13 & 73.83 \\
\hline & 40 & 7515.22 & 13291.25 & 1.77 & 9791.56 & 248.12 & 190.44 & 76.75 \\
\hline \multirow[t]{3}{*}{ CM1DIS } & 60 & 9664.75 & 12538.78 & 1.30 & 13451.66 & 311.55 & 223.84 & 71.85 \\
\hline & 80 & 13123.36 & 11423.16 & 0.87 & 19591.78 & 371.02 & 248.52 & 66.98 \\
\hline & 40 & 8897.93 & 12512.87 & 1.41 & 16597.52 & 401.60 & 215.30 & 53.61 \\
\hline \multirow[t]{2}{*}{ TDIS } & 60 & 10322.34 & 11521.87 & 1.12 & 20230.36 & 431.07 & 219.95 & 51.02 \\
\hline & 80 & 14985.81 & 11318.13 & 0.76 & 30869.30 & 511.40 & 248.27 & 48.55 \\
\hline
\end{tabular}

and $0.84 \mathrm{~kg} / \mathrm{m}^{3}$ compared to $1.77,1.30$, and $0.87 \mathrm{~kg} / \mathrm{m}^{3}$ with CM1DIS and $1.41,1.12$, and $0.76 \mathrm{~kg} / \mathrm{m}^{3}$ (for lateral lengths 40,60 , and 80 meters respectively).

Percentage of water saving varied widely within individual lateral lengths and between circuit types relative to TDIS. Under slope 0\% level CM2DIS water saving percent values were 19.26, 12.48, and $14.03 \%$; with CM1DIS they were $18.51,10.50$, and $12.78 \%$; and under slope level 2\% with CM2DIS they were 19.93, 13.26, and $10.38 \%$ and CM1DIS were 20.49, 13.96, and 13.23 $\%$ (for lateral lengths 40, 60, 80 meters respectively).

\section{REFERENCES}

[1] International Energy Annual (2003) (EIA), Projection, System for the Analysis of Global Energy Markets 2006 (EIA).

[2] Pimentel, D. and Giampietro, M. (1994) Food, Land, Population and the U.S. Economy. Carrying Capacity Network. http://www.dieoff.com/page55.htm
[3] Keller, J. (2002) Evolution of drip/microirrigation: Traditional and non-traditional uses. Paper Presented as Keynote Address at the International Meeting on Advances in Drip/Micro Irrigation, 2 to 5 December 2002, Puerto de la Cruz, Tenerife.

[4] Reyes, M.R. (2007) Agroforestry and sustainable vegetable production in Southeast Asian watersheds. Annual Report, SANREM-CRSP, North Carolina A\&T State University.

[5] Capra, A. and Scicolone, B. (1998) Water quality and distribution uniformity in drip/trickle irrigation systems. Journal of Agriculture Engineering Research, 70, 355365.

[6] FAO (1992) Small-Scale pimped irrigation; energy and cost. Kay, M., Silsoe Collage, U.K. and Hatcho, N., FAO land and Water Development Division, pp. 5-40.

[7] Mizyed, N. and Kruse, E.G. (1989) Emitter discharge evaluation of subsurface trickle irrigation systems. Transactions of the ASAE, 32, 1223-1228.

[8] Kirnak, H., Dogan, E., Demir, S. and Yalcin, S. (2004) Determination of hydraulic performance of trickle irrigation emitters used in irrigation system in the Harran Plain. 
Turkish Journal of Agriculture and Forestry, 28, 223230.

[9] ASAE Standards (2003) EP405.1 FEB03. Design and installation of microirrigation systems. ASAE, St. Joseph.

[10] Wu, I.P. and Gitlin, H.M. (1979) Hydraulics and uniform for drip irrigation. Journal of the Irrigation and Drainage Division, ASCE, 99(IR3), 157-168.

[11] Camp, C.R., Sadler, E.J. and Busscher, W.J. (1997) A comparison of uniformity measure for drip irrigation systems. Transactions of the ASAE, 40, 1013-1020.

[12] Lamm, F.R., Trooien, T.P., Clark, G.A., Stone, L.R., Alam, M., Rogers, D.H. and chlgel, A.J. (2002) Using beef lagoon effluent with SDI. In: Proceedings of Irrigation Association in International Irrigation Technical Conference, 24-26 October 2002, New Orleans, Available from Irrigation Association, Falls Church, Virginia, p. 8. http://www.oznet.ksu.edu/sdi/Reports/2002/MWIAPaper. pdf

[13] Nakayama, F.S. and Bucks, D.A. (1981) Emitter clogging effects on trickle irrigation uniformity. Transactions on ASAE, Vol. 24, No. 1, pp. 77-80.

[14] Talozi, S.A. and Hills, D.J. (2001) Simulating emitter clogging in a microirrigation subunit. Transactions on ASAE, Vol. 44, No. 6, pp. 1503-1509.
[15] Berkowitz, S.J. (2001) Hydraulic performance of subsurface wastewater drip systems. In: On-Site Wastewater Treatment: Proceedings of 9th International Symposium on Individual and Small Community Sewage Systems, ASAE, St. Joseph, 583-592.

[16] Warrick, A.W. and Yitayew, M. (1988) Trickle lateral hydraulics. I: Analytical solution. Journal of Irrigation and Drainage Engineering, ASCE, 114(2), 281-288.

[17] Hathoot, H.M., Al-Amoud, A.I. and Mohammed, F.S. (1991) Analysis of a pipe with uniform lateral flow. Alexandria Engineering Journal, Alexandria, 30(1), C49$\mathrm{C} 54$.

[18] Hathoot, H.M., Al-Amoud, A.I. and Mohammed, F.S. (1993) Analysis and design of trickle irrigation laterals. Journal of the Irrigation and Drainage Division, 119(5), 756-767.

[19] Watters, G.Z. and Keller, J. (1978) Trickle irrigation tubing hydraulics. ASAE Technical, St. Joseph.

[20] Gee, G.W. and Bauder, J.W. (1986) Particle size analysis. Methods of soil analysis. Part 1. Agron. 2nd Edition, ASA and SSSA, Madison, 383-412.

[21] Jackson, M.L. (1967) Soil chemical analysis. Prentice Hall, Inc., Englewood Cliffs. 